\title{
Análise experimental da endentação de membranas hiperelásticas com e sem atrito.
}

\section{Experimental Analysis of Friction and Frictionless Endentation on Hyperelastic Membranes}

Projeto de Graduação

Trabalho apresentado ao final do curso de Engenharia Mecânica do Departamento de Engenharia Mecânica PUC - Rio como parte dos requisitos à conclusão do curso de Engenharia Mecânica.

Orientador: Hans Ingo Weber Co-orientador: Djenane Cordeiro Pamplona 
Ao meu orientador Hans I.Weber e minha Co-orientadora Djenane C. Pamplona, pela oportunidade e proposta do projeto, e por toda a disponibilidade e ensinamentos passados, tornando possíveis a conclusão deste projeto e a minha formação.

A todos os professores que despertaram em mim ainda mais a paixão pelo conhecimento com sabedoria, dedicação e didática, servindo de exemplo e referência acadêmica para mim, em especial aos professores Carlos Alberto de Almeida e Geraldo Monteiro Sigaud (em memória).

Aos meus pais, por todo o apoio, carinho, perseverança e amor que, com seus ensinamentos, ajudaram a me tornar quem sou hoje. Amo vocês.

A todos os amigos que fiz na PUC, que com certeza levarei para toda a vida, por todo o apoio durante as fases mais diversas da minha caminhada na faculdade.

A todos os meus amigos e pessoas que me motivaram de alguma forma a conseguir alcançar esse objetivo. Muito obrigado.

"O conhecimento nos faz responsáveis"

Che Guevara 


\section{Resumo}

Este trabalho tem como objetivo o estudo experimental de membranas planas hiperplásticas submetidas a endentação e perfuração transversalmente ao seu plano indeformado, levando em conta o efeito do atrito na interface entre a membrana e o endentor. Esta análise levando em conta o efeito do atrito foi inicialmente proposta na tese de mestrado do aluno Guilherme Rodrigues Sampaio, onde foram feitos estudos e comparações numéricas e experimentais na endentação de membranas hiperelásticas. Para a análise numérica, foi utilizado o programa computacional Abaqus CAE e foram desenvolvidos aparatos experimentais para a realização de testes.

Neste projeto foram realizados ensaios experimentais com o objetivo de uma melhor validação dos resultados numéricos, desta vez com a utilização da máquina Instron ${ }^{\circledR}$ 3343, que permite a realização de testes de endentação com melhor precisão e confiabilidade.

Palavras-chave: endentação, membranas, atrito, borracha, experimental 


\begin{abstract}
This study aims on the experimental analysis of hyperelastic flat membranes submitted to endentation and penetration transversally its undeformed plane, considering friction effects between the membrane-endentor surface. This analysis considering the friction effect was first proposed by Guilherme Rodrigues Sampaio on his master's thesis, where numerical and experimental studies and comparisons were made in hyperelastic flat membranes under indentation tests. For the numerical analysis, the Abaqus CAE finite elements software was used, and experimental apparatus were developed for the tests.
\end{abstract}

On this job it was performed experimental tests with the goal of improving the validation of the numerical results, now using the Instron ${ }^{\circledR} 3343$ machine, providing more accurate and reliable indentation tests.

Keywords: endentation, membrane, friction, rubber, experimental 


\section{Sumário}

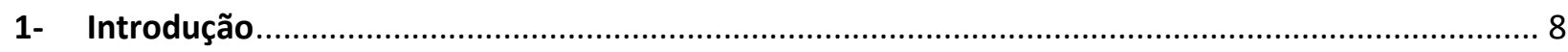

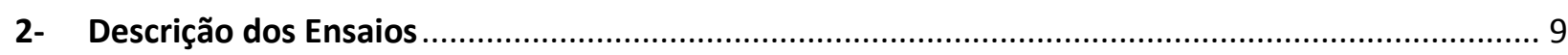

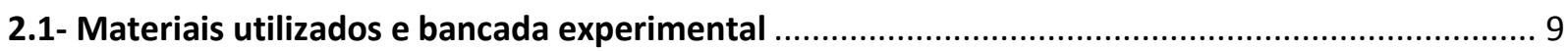

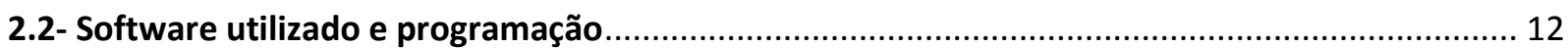

3-Resultados experimentais dos ensaios sem lubrificante, com lubrificante e com lixa 600 ........................ 15

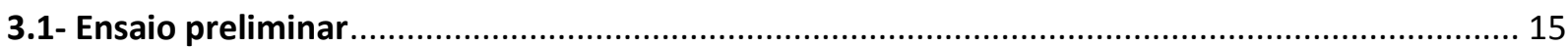

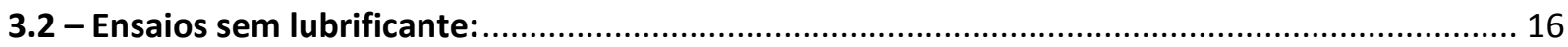

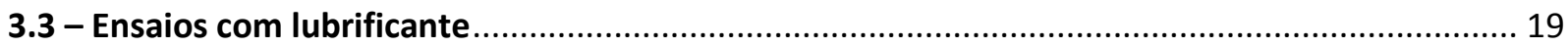

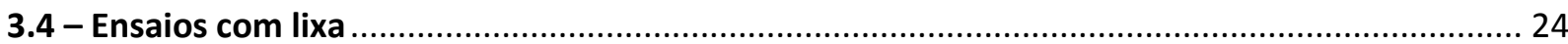

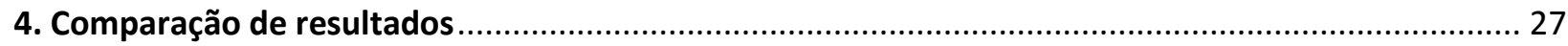

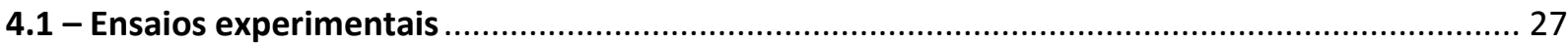

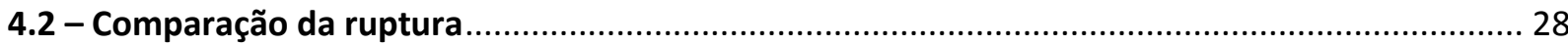

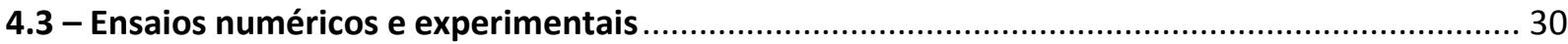

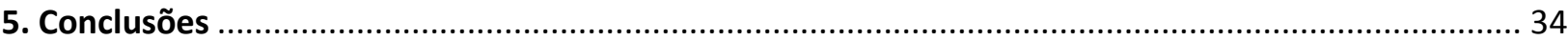

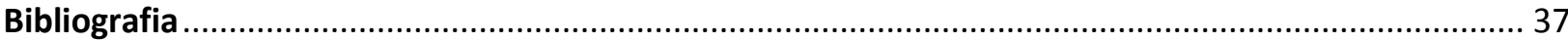

\section{Índice de figuras}

Figura 1 Membrana de borracha Angelus Hevea - alta resistência ........................................................ 9

Figura 2 (a) Máquina de ensaios Instron ${ }^{\circledR}$ modelo 3343 (b) Base de acrílico. ............................................. 10

Figura 3 Anéis de acrílico confeccionados na máquina de corte laser................................................. 10

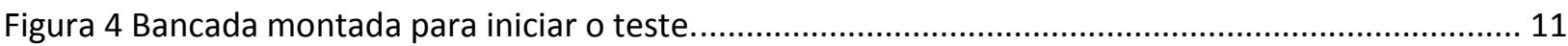

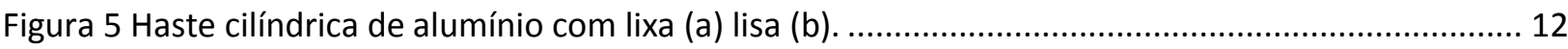

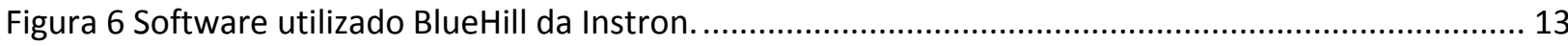

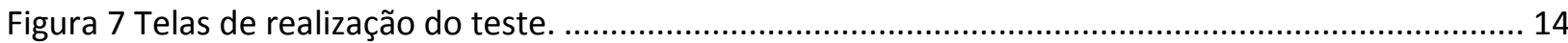

Figura 8 Membrana sendo ensaiadas (a) sem carga, (b) início da endentação, (c) endentação continuada.

Figura 9 Resultados do ensaio preliminar de endentação.

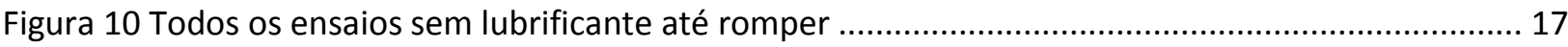

Figura 11(a) e (b). Todos os ensaios sem lubrificante até $60 \mathrm{~mm}$..................................................... 17

Figura 12 Endentação até o rompimento da membrana pré-condicionada.............................................. 18

Figura 13 Média de todos os ensaios sem lubrificante sem o primeiro ensaio......................................... 19 
Figura 14 Resultados dos testes de endentação até $200 \mathrm{~mm}$ de extensão.

Figura 15 Teste com a mesma membrana de pré-condicionamento até $120 \mathrm{~mm}$, com só uma lubrificação, seguido de endentação até $200 \mathrm{~mm}$.

Figura 16 Resultados do carregamento com a mesma membrana de pré-condicionamento até $120 \mathrm{~mm}$, com só uma lubrificação, seguido de endentação até $200 \mathrm{~mm}$.

Figura 17 Resultados dos ciclos de pré-condicionamento até $40 \mathrm{~mm}$, com relubrificação entre carregamentos.

Figura 18 Resultados dos ciclos de pré-condicionamento até $60 \mathrm{~mm}$, com relubrificação entre carregamentos.

Figura 19 Média de todos os resultados com lubrificante até $60 \mathrm{~mm}$ sem o primeiro ensaio. ................ 23

Figura 20 Haste cilíndrica de alumínio com lixa (a) lisa (b). ................................................................. 24

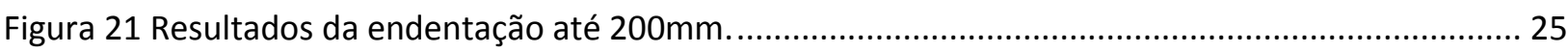

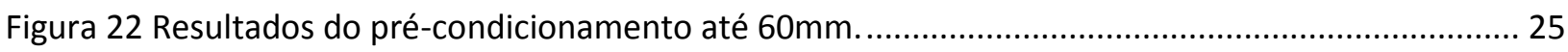

Figura 23 Média de todos os resultados até $60 \mathrm{~mm}$ com lixa .............................................................. 26

Figura 24 Comparação de ensaios repetidos, sem lubrificante (a), com lubrificante (b) e com lixa (c).... 27

Figura 25 Comparação de ensaios repetidos, sem lubrificante (a), com lubrificante (b) e com lixa (c).... 28 Figura 26 Comparação das rupturas das membranas sem lubrificante (a), com lubrificante (b) e com lixa (c)...

Figura 27 Comparação dos perfis das membranas deformadas em $41 \mathrm{~mm}$, com lixa (a), sem lubrificante (b) e com lubrificante (c) tomando como base de comparação o perfil (c)............................................. 29 Figura 28 Fotos dos perfis das membranas deformadas em $41 \mathrm{~mm}$, com lubrificante (a), sem lubrificante

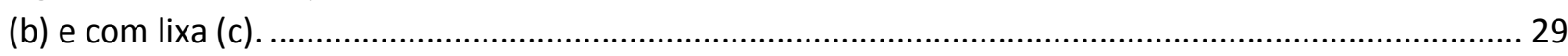

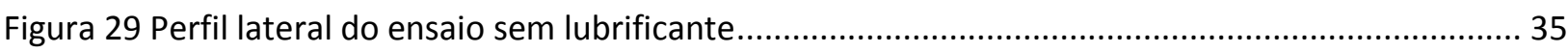

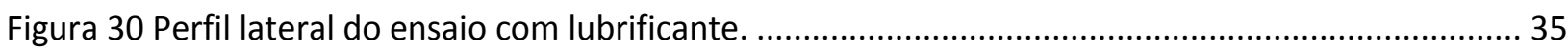

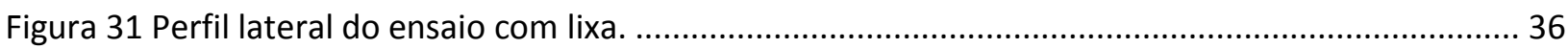

Figura 32 Ensaios e retas tangentes aos primeiros pontos de inflexão. .................................................... 36 


\section{Índice de tabelas}

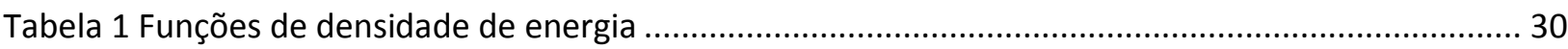

Tabela 2 Comparação dos resultados numéricos e experimentais, material Mooney-Rivlin .................... 31

Tabela 3 Comparação dos restulador numéricos e experimentais, material Neo Hookeano ................... 32

Tabela 4 Comparação dos resutlados numéricos e experimentais, material Ogden ordem 1 ................. 33

Tabela 5 Comparação dos resultados numéricos e experimentais, material Ogden ordem 2 ................. 33 


\section{1- Introdução}

O estudo do comportamento de membranas vem recebendo nos últimos anos uma notável atenção em razão da variada aplicabilidade de membranas nas mais diversas áreas da engenharia, incluindo atuadores, robótica, sensores, aeroespacial, bioengenharia e estruturas infláveis para engenharia civil.

A teoria de membranas possui ainda uma grande aplicação na área biomédica caracterizando diversos tecidos biológicos, levando a publicação de inúmeros trabalhos relevantes nas últimas décadas.

O problema de endentação e penetração em membranas já foi abordado em outros trabalhos recentes, contudo, nenhum destes considera os efeitos do atrito na interação entre as estruturas que compreendem o problema. Este trabalho busca apresentar uma análise numérica e experimental que compare os efeitos do atrito com a simplificação que desconsidera. A análise de endentação, penetração e por fim a ruptura de membranas tem grande importância em diversos setores da indústria. Nos últimos anos diversas pesquisas e produtos foram desenvolvidos com membranas. Estas, tem obtido um espaço cada vez maior nas aplicações, sobretudo para uso de estruturas provisórias infláveis e tensionadas. As estruturas de membrana aliam praticidade, facilidade de transporte e baixo peso quando comparadas com estruturas totalmente rígidas. $\mathrm{O}$ contexto deste trabalho foi dar suporte à parte experimental desta linha de pesquisa. 


\section{2- Descrição dos Ensaios}

\section{1- Materiais utilizados e bancada experimental}

Para a análise experimental foram utilizadas membranas de borracha Angelus Hevea alta resistência, Fig.1. Elas possuem formato quadrado, $125 \mathrm{~mm}$ de lado e a medição da espessura realizada no laboratório de metrologia da PUC-Rio (feito com o uso de um micrômetro manual) em diferentes pontos de 5 amostras de membrana, apresentou um valor médio de $0,18 \mathrm{~mm}$.

Os testes foram realizados numa máquina de ensaios Instron ${ }^{\circledR}$ modelo 3343 , projetada para ensaios de tração e compressão, Fig. 2 (a). Este equipamento possui capacidade de extensão de até $1500 \mathrm{~mm}$ e de carga aplicada de até $50 \mathrm{~N}$. Esta configuração de pequenas cargas e grandes deslocamentos é essencial para a caracterização de materiais hiperelásticos, como o látex utilizado. Para os ensaios propriamente ditos foi confeccionada uma base de acrílico, com $250 \mathrm{~mm}$ de altura, lados da base de $167 \mathrm{~mm}$ e espessura de $12 \mathrm{~mm}$ (todas as placas), Fig.2(b).

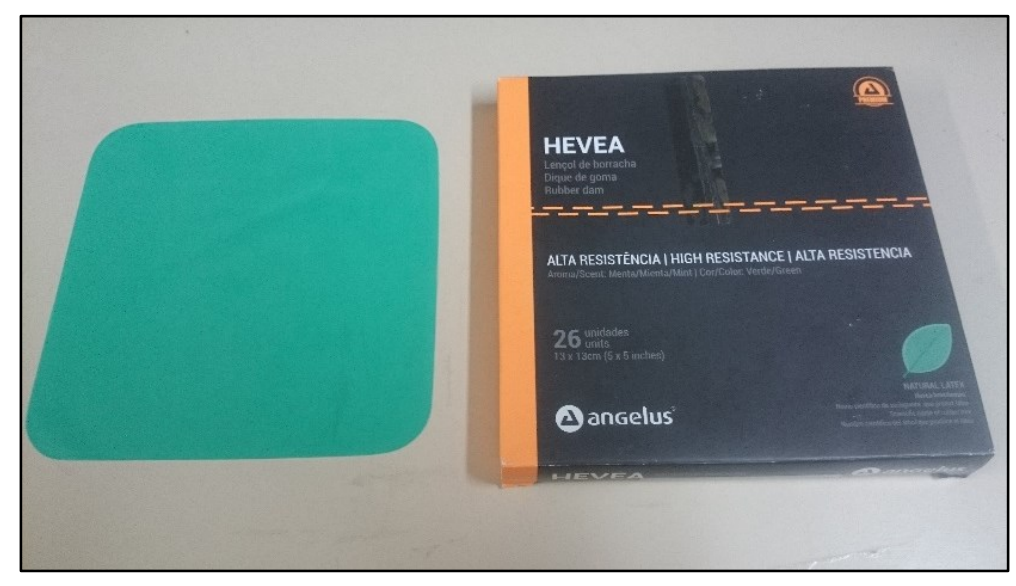

Figura 1 Membrana de borracha Angelus Hevea - alta resistência 
Nesta base de acrílico são fixadas as membranas circulares a serem testadas. A fixação das membranas é feita utilizando anéis de acrílico com diâmetro externo e interno de $15 \mathrm{~cm}$ e $12 \mathrm{~cm}$ respectivamente, neles são feitos 8 furos, Fig. 3.

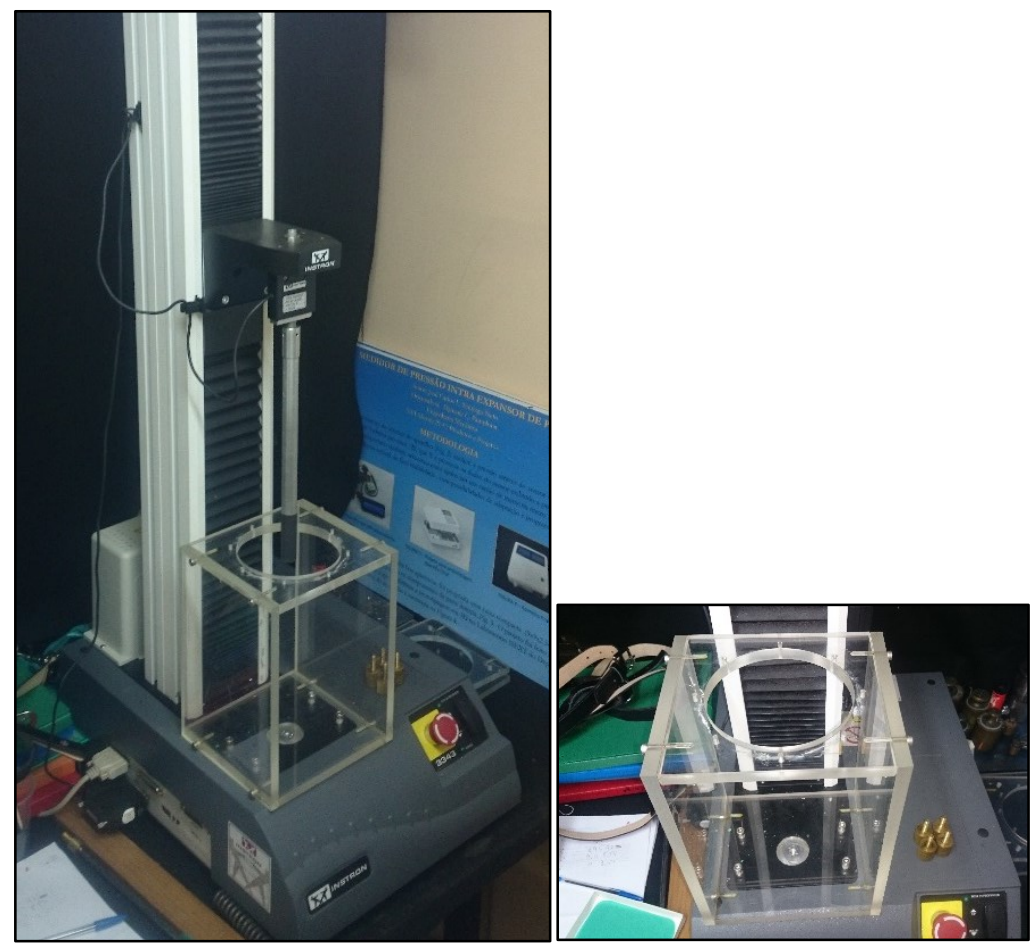

Figura 2 (a) Máquina de ensaios Instron ${ }^{\circledR}$ modelo 3343 (b) Base de acrílico.

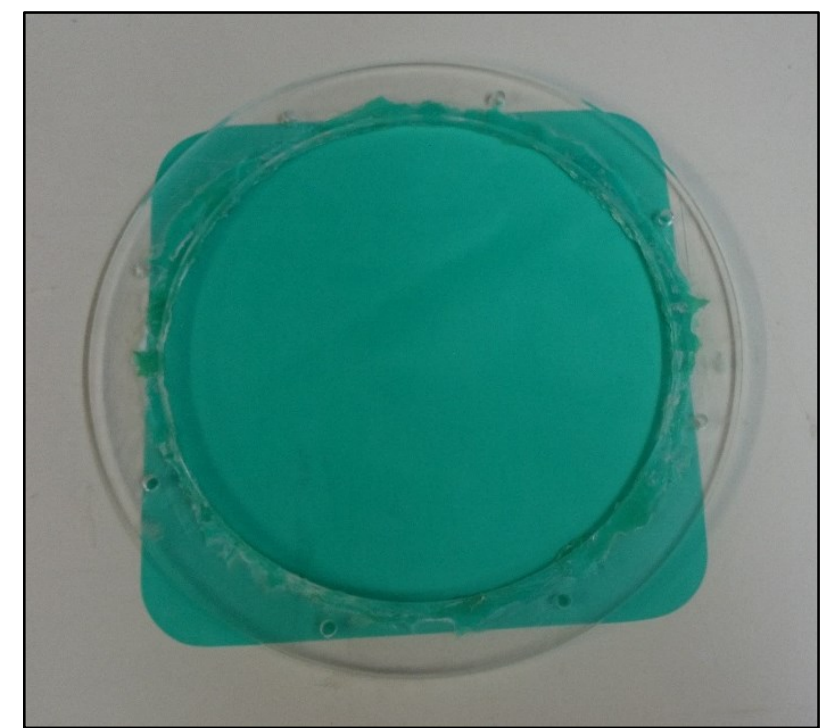

Figura 3 Anéis de acrílico confeccionados na máquina de corte laser. 
Nos anéis são coladas as membranas com cola do tipo super-bonder e em seguida afixadas na base da máquina através dos furos. Para garantir que as membranas permaneçam planas, aplica-se o super-bonder nos anéis de acrílico e este é levado até às membranas, que repousam em uma superfície plana, para poder centralizar e colar as membranas nos anéis com o objetivo de evitar uma má colagem e comprometer o formato plano relaxado das membranas.

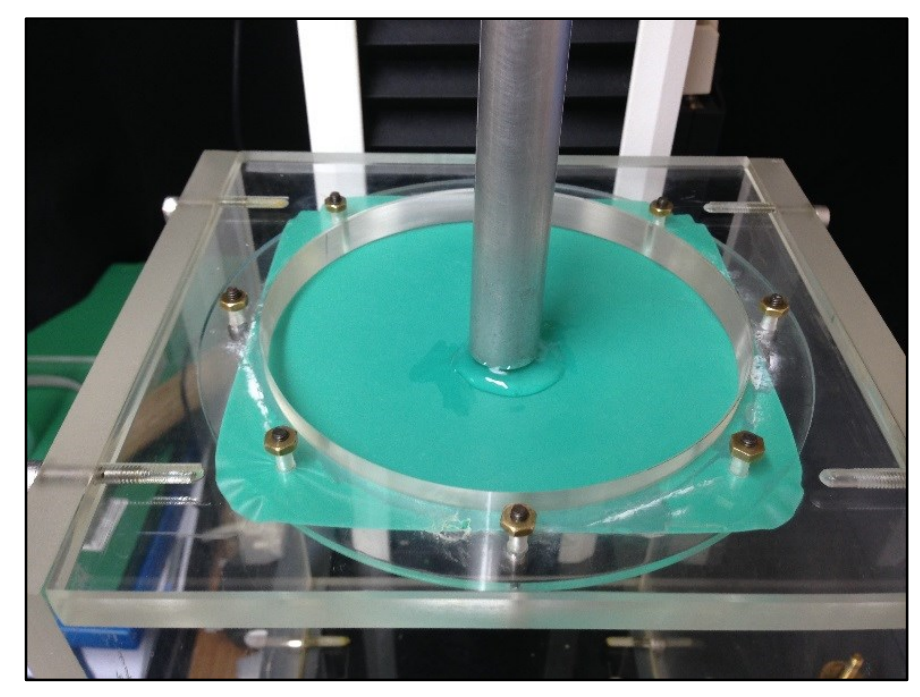

Figura 4 Bancada montada para iniciar o teste.

O conjunto anel-membrana é levado à base da máquina e fixado através de parafusos. Com a realização destes passos, a bancada estará pronta para o início dos testes, Fig. 4, que exemplifica um ensaio lubrificado. 


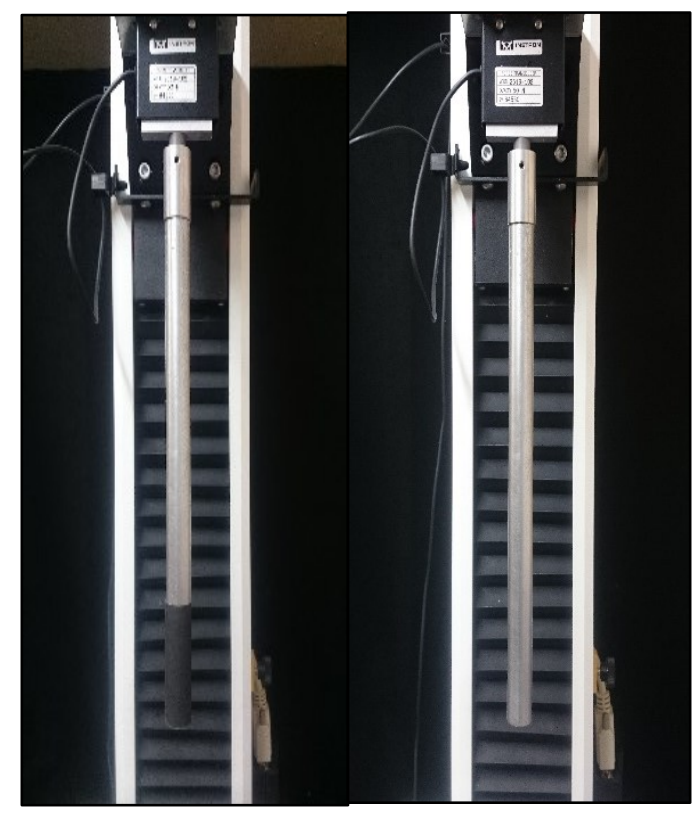

Figura 5 Haste cilíndrica de alumínio com lixa (a) lisa (b).

A endentação foi realizada na Instron por uma haste cilíndrica de alumínio com $28,4 \mathrm{~cm}$ de comprimento e $1,8 \mathrm{~cm}$ de diâmetro, Fig. 5(a) onde no caso do ensaio com lixa foi colada com fita dupla face $3 \mathrm{M}$ a lixa 600 , até a altura de $5,9 \mathrm{~cm}$ da ponta do endentor, Fig. 5(b).

\section{2- Software utilizado e programação}

O software utilizado foi o BlueHill da Instron, que permite a interação da máquina com o usuário através da programação pelo computador e realização de testes. Assim que o software é inicializado, deve-se zerar a carga percebida pela célula de carga, e para isso clica-se no botão circulado na Fig. 6 e seleciona-se a opção equilibrar carga. 


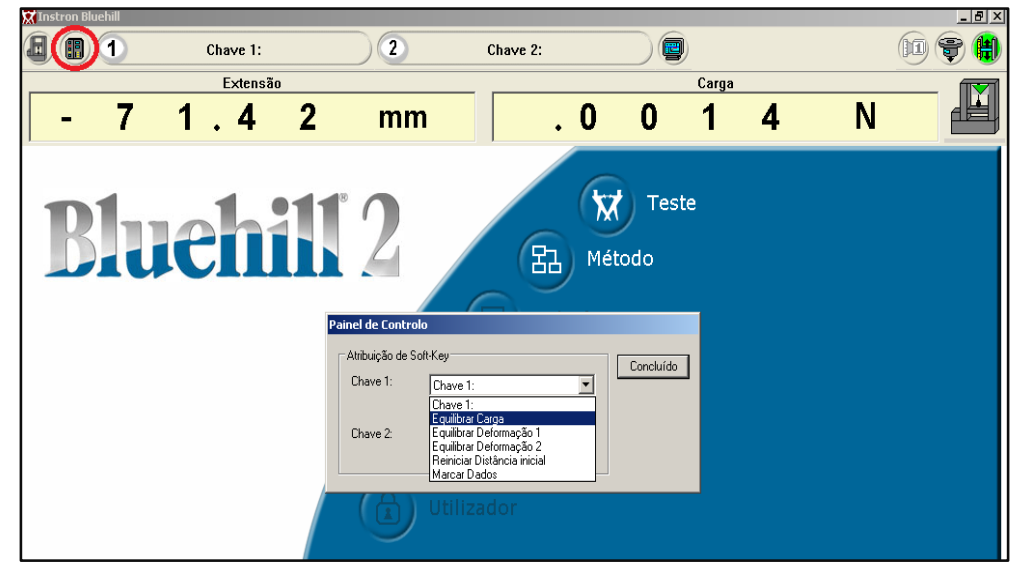

Figura 6 Software utilizado BlueHill da Instron.

Para a configuração de um novo teste, clicamos na aba métodos, sub aba controlo, onde é possível escolher os tipos básicos de testes a serem realizados (como tração e compressão ou o tipo de variável de controle, como carga ou deslocamento, por exemplo), bem como pré-testes (pré-condicionamento com ciclos de carregamentos e descarregamentos) e por fim escolher os parâmetros para identificar o final do teste (como uma variação brusca na carga indicadora de rompimento da membrana, ou um valor máximo de extensão desejado da mesma). Uma vez escolhidos todos os métodos e parâmetros do teste, podemos salvar e guardar o mesmo no programa e usá-lo posteriormente.

Uma vez programado o teste, clica-se na aba teste, seleciona-se a rotina desejada e inicia-se o teste. Concluído o teste, deve-se retornar o endentor à posição inicial (definida na configuração do teste) antes de começar um novo ensaio. 

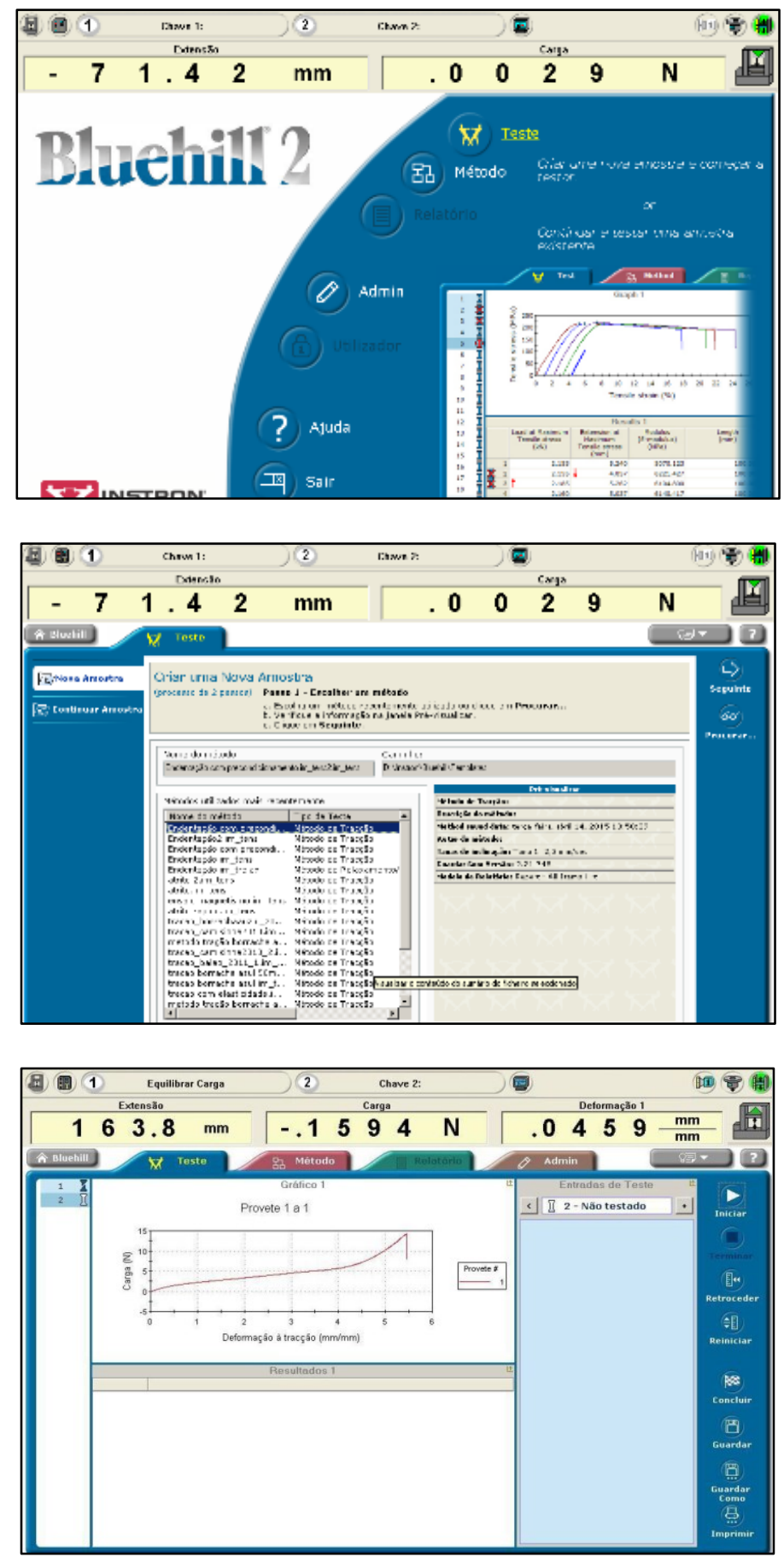

Figura 7 Telas de realização do teste. 


\section{3-Resultados experimentais dos ensaios sem lubrificante, com lubrificante e com lixa 600}

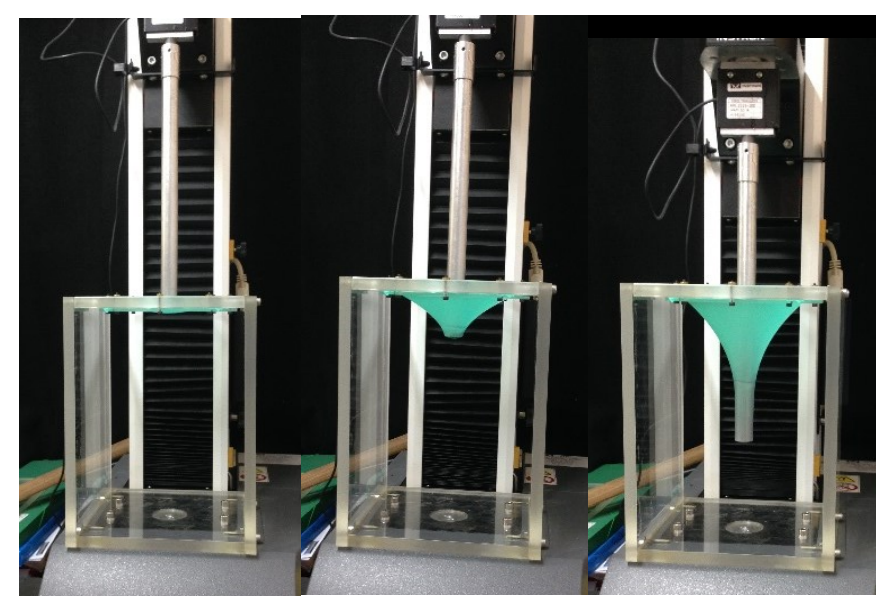

Figura 8 Membrana sendo ensaiadas (a) sem carga, (b) início da endentação, (c) endentação continuada.

A membrana nos ensaios com lixa tomou a forma apresentada nas figuras, Fig. 8 (a, b, c). As formas do ensaio com e sem lubrificante são semelhantes, porém para cargas menores.

\section{1- Ensaio preliminar}

Primeiro ensaio na Instron e Bluehill. Foram realizados 3 testes de endentação contínua sem lubrificação até romper (200mm de extensão). As membranas romperam por volta de 140mm de extensão pois eram as membranas azuis antigas, da marca White Duflex. Os ensaios não se mostraram repetíveis e como não sabíamos se era por estarem as membranas velhas ou por serem de qualidade inferior, a marca e tipo foi substituída pela membrana Angelus Hevea alta resistência. 


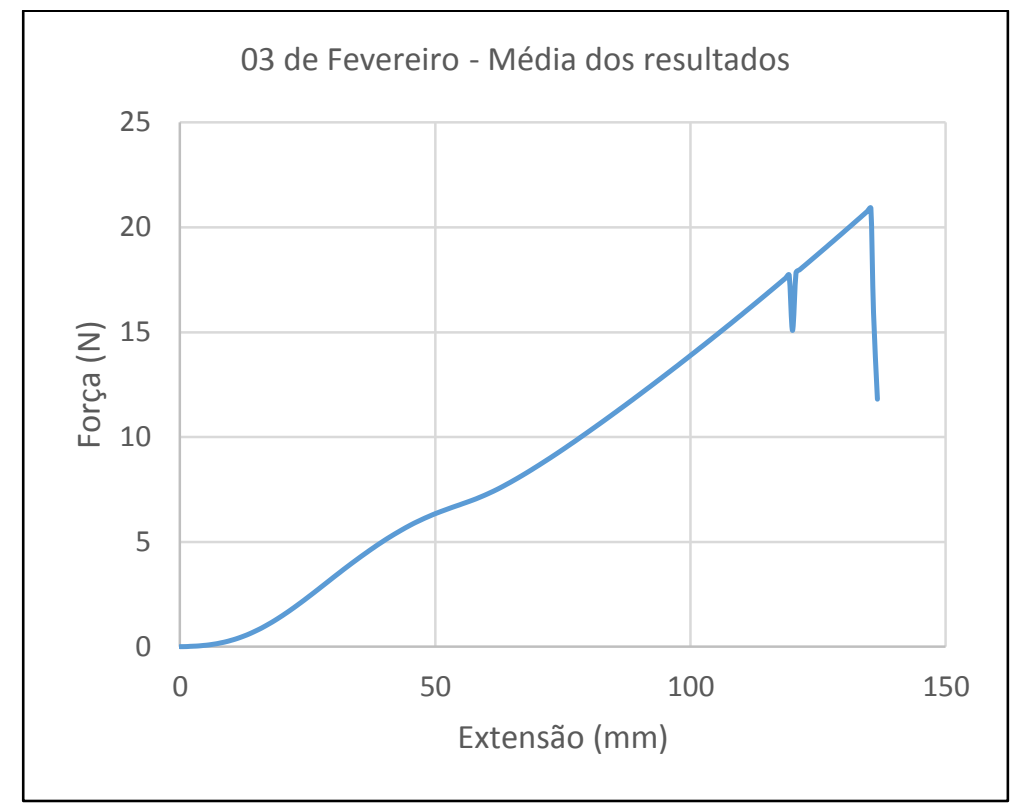

Figura 9 Resultados do ensaio preliminar de endentação.

\section{2-Ensaios sem lubrificante:}

Para membranas sem lubrificante foram realizados dois tipos de testes:

- Dia 09/03

1) Cinco testes de endentação contínua, cada um com uma membrana, Fig. 10, sem lubrificação até $200 \mathrm{~mm}$ de extensão. As membranas romperam entre $170 \mathrm{~mm}$ e $200 \mathrm{~mm}$ de extensão (o teste que chegou até 200mm não rompeu), Fig. 10. 


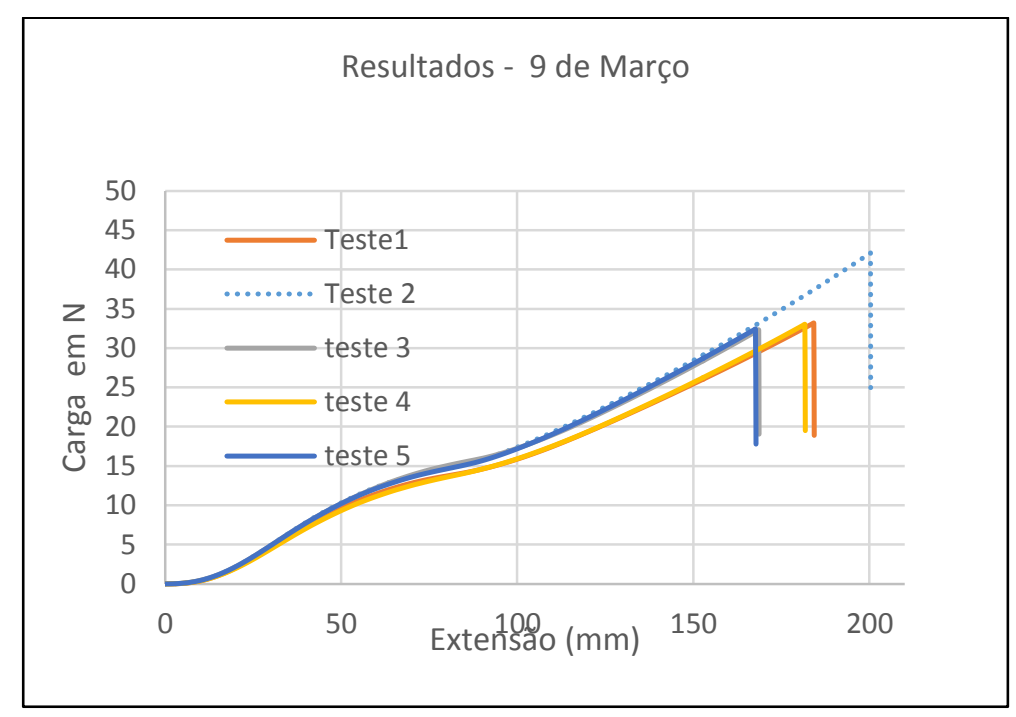

Figura 10 Todos os ensaios sem lubrificante até romper

2) Cinco testes de repetição com uma mesma membrana, i.e., com précondicionamento. Foram feitas 5 extensões até $60 \mathrm{~mm}$, onde ao final de cada uma a carga era removida completamente, Fig. 11a. Ao final destes 5 pré condicionamentos, foi realizado na mesma membrana um sexto teste até $200 \mathrm{~m}$ de extensão máxima, até a membrana romper, Fig. 12.

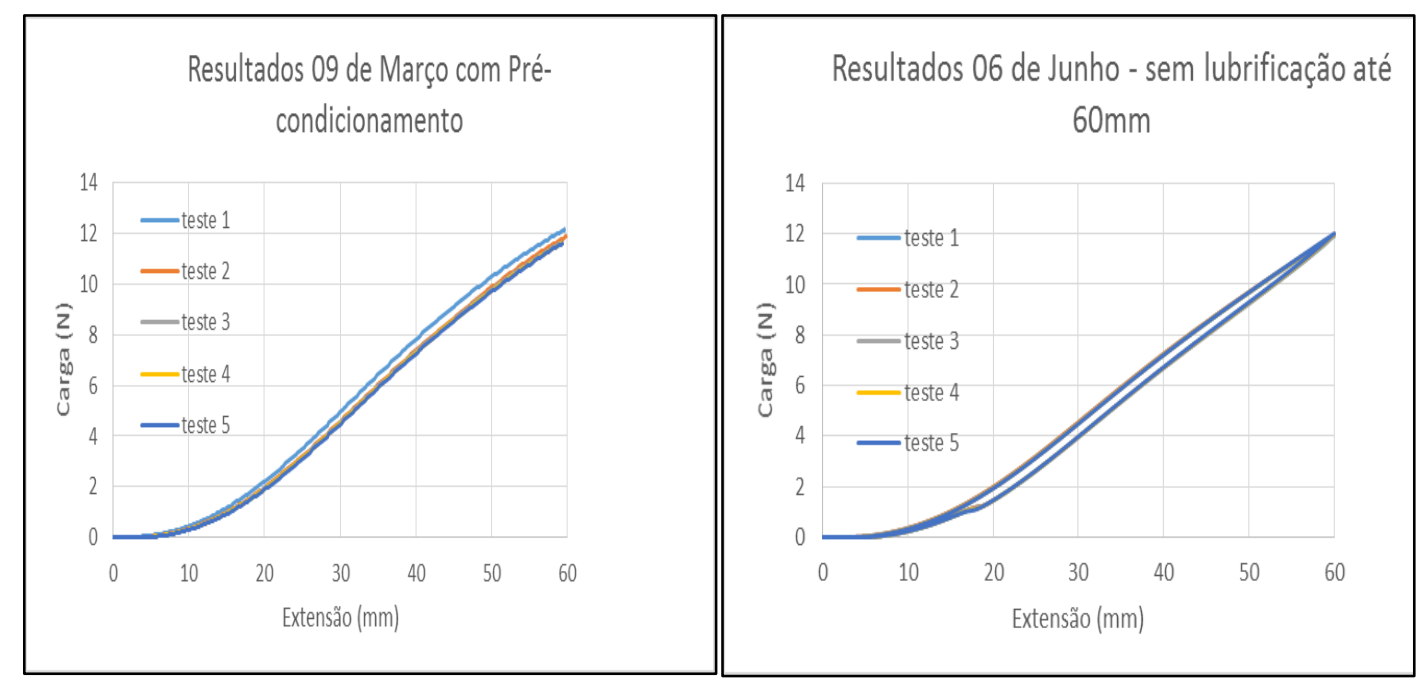

Figura 11(a) e (b). Todos os ensaios sem lubrificante até $60 \mathrm{~mm}$. 


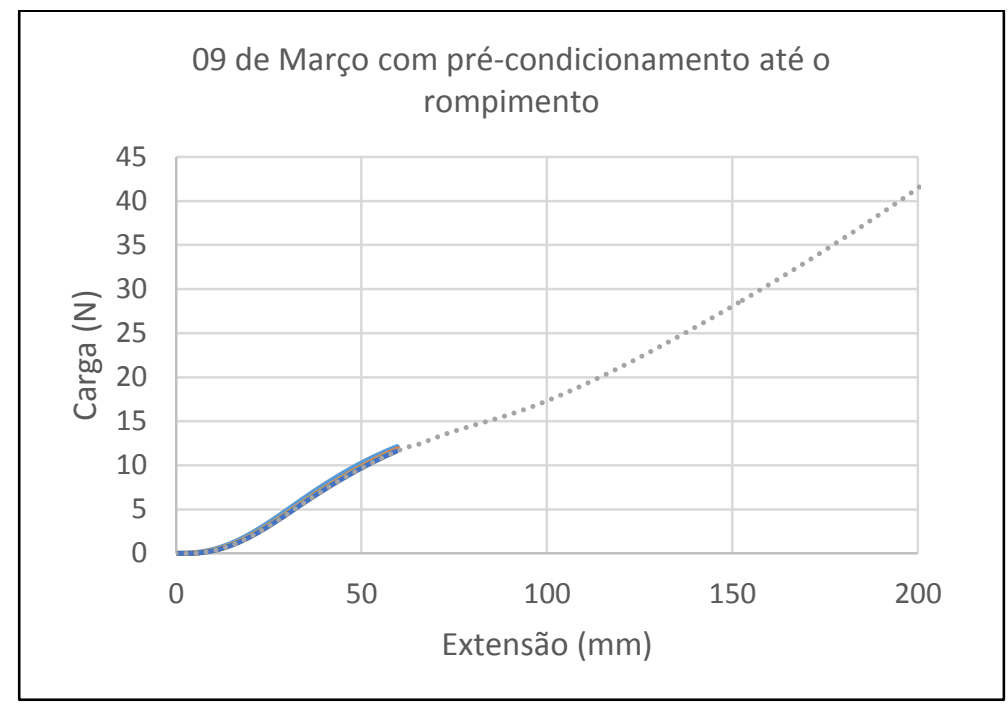

Figura 12 Endentação até o rompimento da membrana pré-condicionada.

Podemos verificar que em todos os ensaios, Fig. 10, o rompimento ocorreu para diferentes extensões, sendo estes na faixa entre $167 \mathrm{~mm}$ e $182 \mathrm{~mm}$, e com carga de rompimento de aproximadamente $32 \mathrm{~N}$.

- Dia 01/06

1) Cinco testes de endentação com pré-condicionamento em uma única membrana, Fig. 11b, com extensão até $60 \mathrm{~mm}$. Foi realizado um ensaio de carregamento e descarregamento cíclico. Percebe-se do resultado que não há significativa variação entre os valores de carga máxima ao longo dos ciclos de carregamento e descarregamento.

Através dos resultados percebemos que não ocorre uma significativa mudança nos valores de carga máxima para um pré-condicionamento de $60 \mathrm{~mm}$ de extensão. Logo, podemos concluir que não há necessidade de realizar pré-condicionamento nos ensaios de endentação sem lubrificante. 


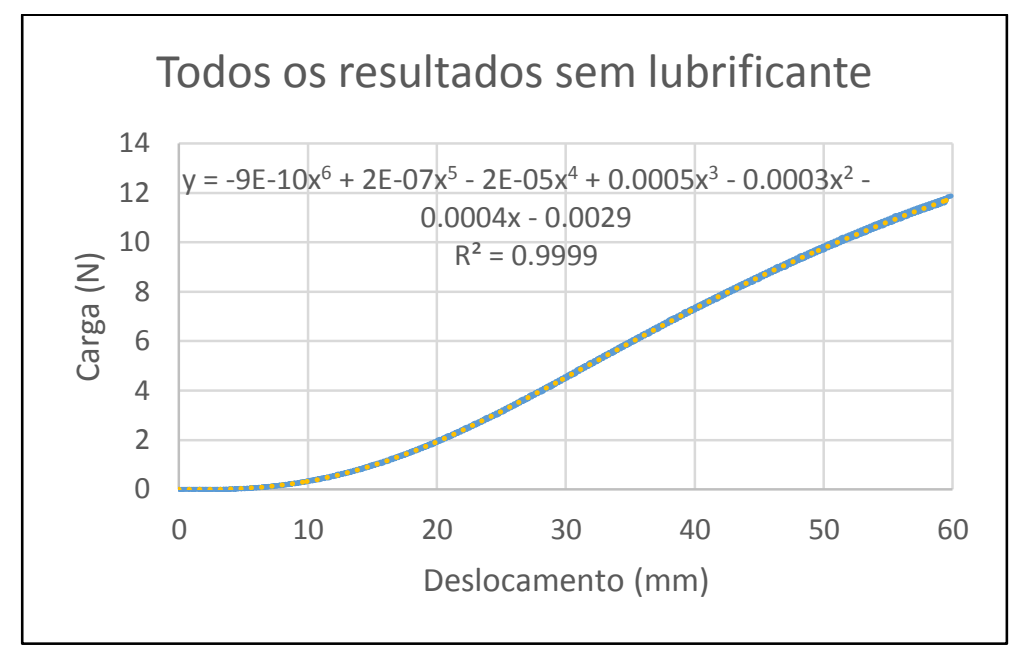

Figura 13 Média de todos os ensaios sem lubrificante sem o primeiro ensaio.

\section{3 - Ensaios com lubrificante}

Para a realização dos ensaios com lubrificante, após a montagem do experimento, antes do início do teste, foram colocados com uma seringa $5 \mathrm{ml}$ de lubrificante $K Y$ na superfície da membrana que entra em contato com o endentor. No ensaio do dia 24/3 não houve relubrificação entre cada ciclo de pré-condicionamento.

- Dia 24/03

Foram feitos dois tipos de testes:

1) Cinco testes de endentação contínuas com lubrificante, cada um com uma membrana, até $200 \mathrm{~mm}$ de extensão. A grande maioria dos testes não rompeu até a conclusão do teste, e alguns testes só romperam durante o descarregamento do endentor, Fig. 14. 


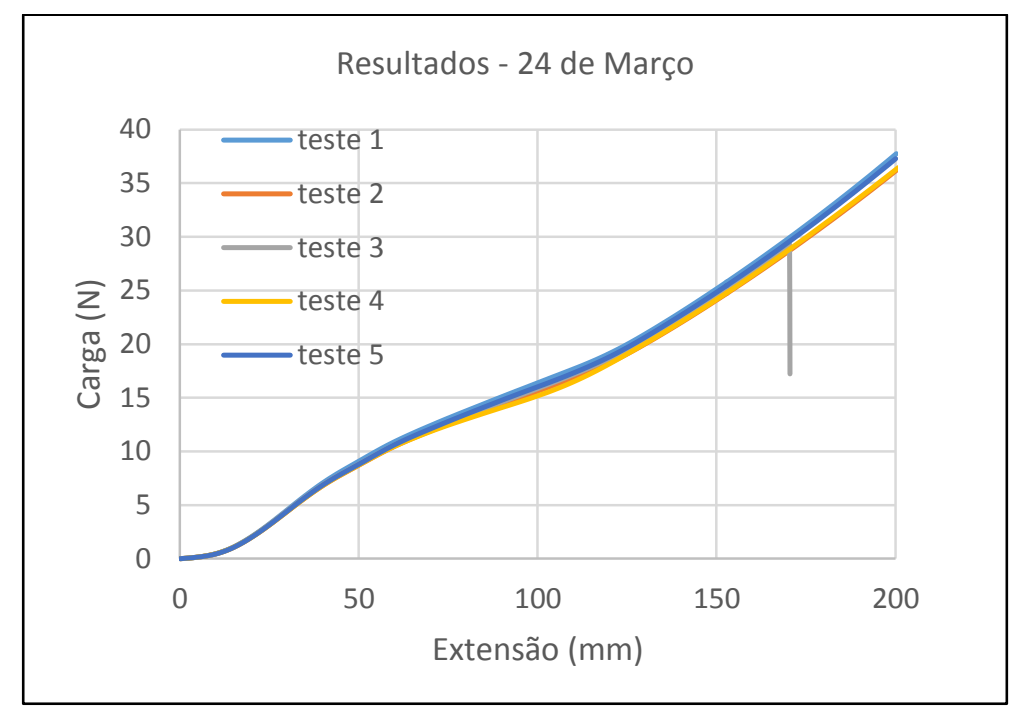

Figura 14 Resultados dos testes de endentação até $200 \mathrm{~mm}$ de extensão.

Podemos verificar que somente o teste 3 rompeu, com uma extensão de $170 \mathrm{~mm}$, enquanto as demais membranas tiveram extensão até $200 \mathrm{~mm}$ (critério de fim de teste). Verificou-se que algumas delas romperam durante o descarregamento, com o alívio de carga.

2) Um teste contínuo com 5 ciclos de pré-condicionamento lubrificado até $120 \mathrm{~mm}$ de extensão. Foi feita somente uma lubrificação em uma única membrana. Figura 15 mostra os ciclos de carregamento e descarregamento na mesma membrana com uma lubrificação única inicial. 


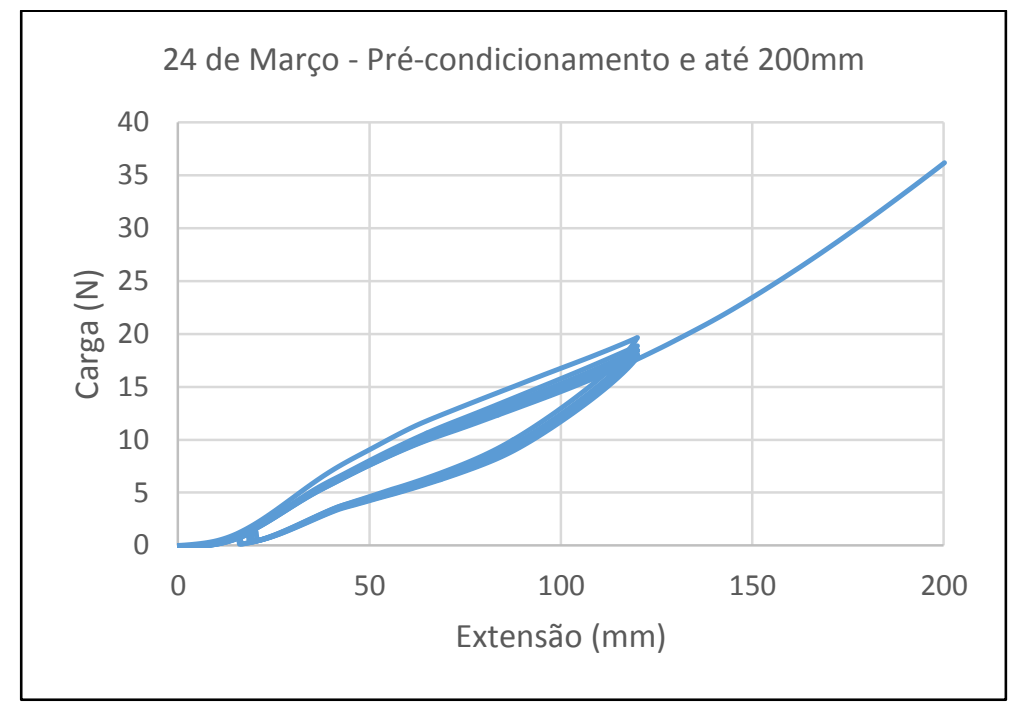

Figura 15 Teste com a mesma membrana de pré-condicionamento até 120 mm, com só uma lubrificação, seguido de endentação até $200 \mathrm{~mm}$.

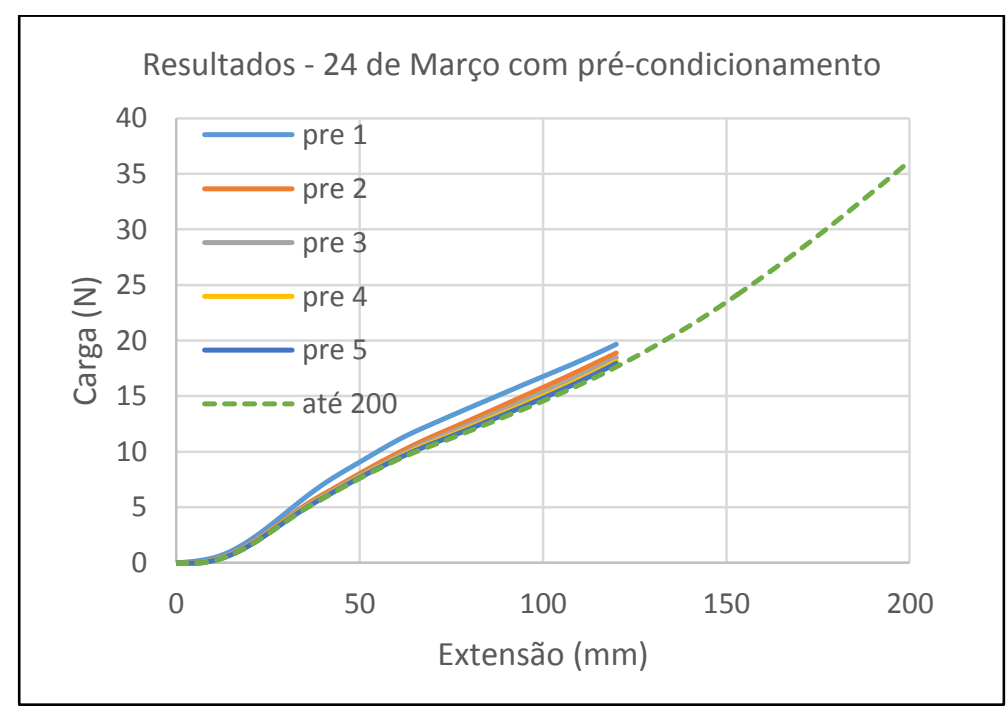

Figura 16 Resultados do carregamento com a mesma membrana de pré-condicionamento até $120 \mathrm{~mm}$, com só uma lubrificação, seguido de endentação até $200 \mathrm{~mm}$.

Figura 16 mostra os resultados do carregamento na mesma membrana com uma lubrificação única inicial. Os resultados obtidos apontaram uma variação grande entre os valores das máximas cargas no primeiro e no último carregamento, a priori sugerindo importância em realizar pré-condicionamento. Surgiu então a dúvida se a relubrificação entre cada ciclo seria importante ou não, e foram feitos outras rodadas de testes para averiguar essa questão. 
- Dia 14/04

Foram feitos dois tipos de testes:

1) Cinco testes de endentação com lubrificação de uma única membrana até $40 \mathrm{~mm}$ de extensão. Desta vez entre cada ciclo de pré condicionamento houve relubrificação da membrana. Foram medidas as curvas de carregamento e descarregamento, Fig. 17. Não foi feito nenhum teste posterior até o rompimento da membrana.

2) Cinco testes de endentação com pré condicionamento com lubrificação de uma única membrana até $60 \mathrm{~mm}$ de extensão. Desta vez entre cada ciclo de pré condicionamento houve relubrificação da membrana. Foram medidas as curvas de carregamento e descarregamento, Fig. 18. Não foi feito nenhum teste posterior até o rompimento da membrana.

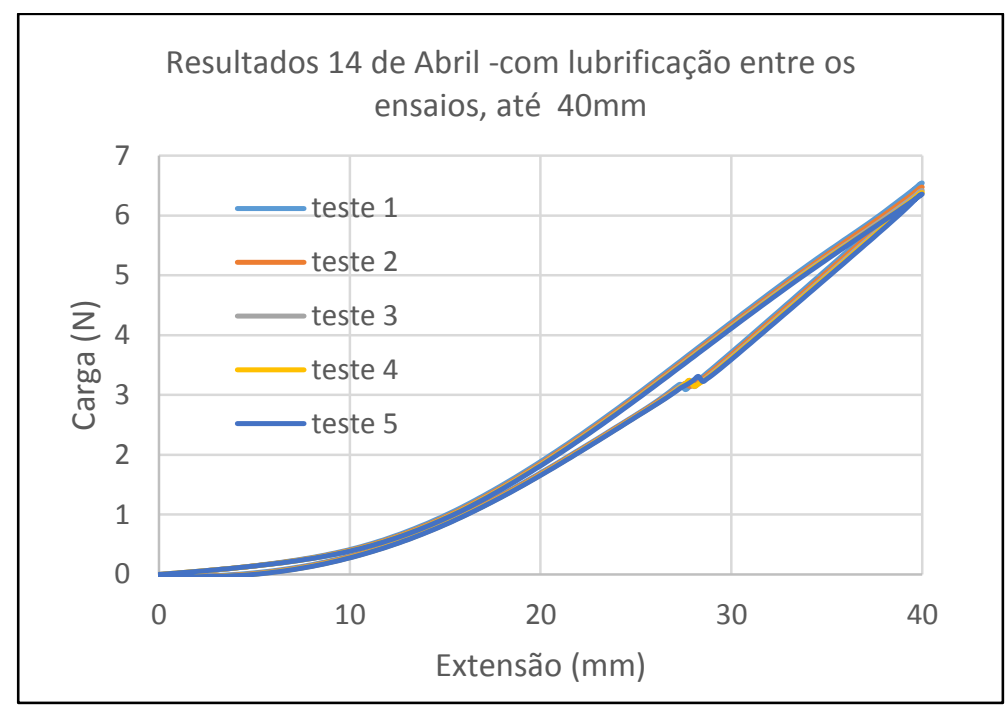

Figura 17 Resultados dos ciclos de pré-condicionamento até $40 \mathrm{~mm}$, com relubrificação entre carregamentos. 


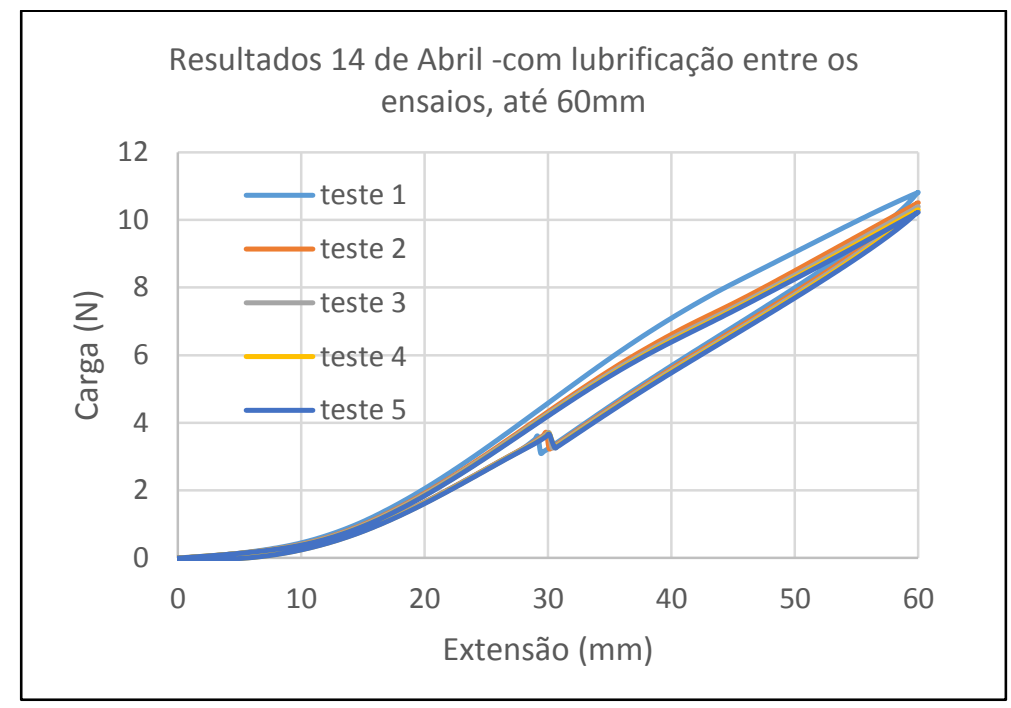

Figura 18 Resultados dos ciclos de pré-condicionamento até $60 \mathrm{~mm}$, com relubrificação entre carregamentos.

Com os resultados obtidos percebe-se que a relubrificação se mostrou necessária para a realização correta do experimento. Com a relubrificação, o efeito de histerese entre as cargas em cada ciclo de carregamento e descarregamento diminuiu, quando comparado com os ensaios sem relubrificação, provavelmente devido ao fato de o efeito do lubrificante diminuir ao longo dos ciclos. Logo, a relubrificação se mostrou válida entre cada pré-condicionamento.

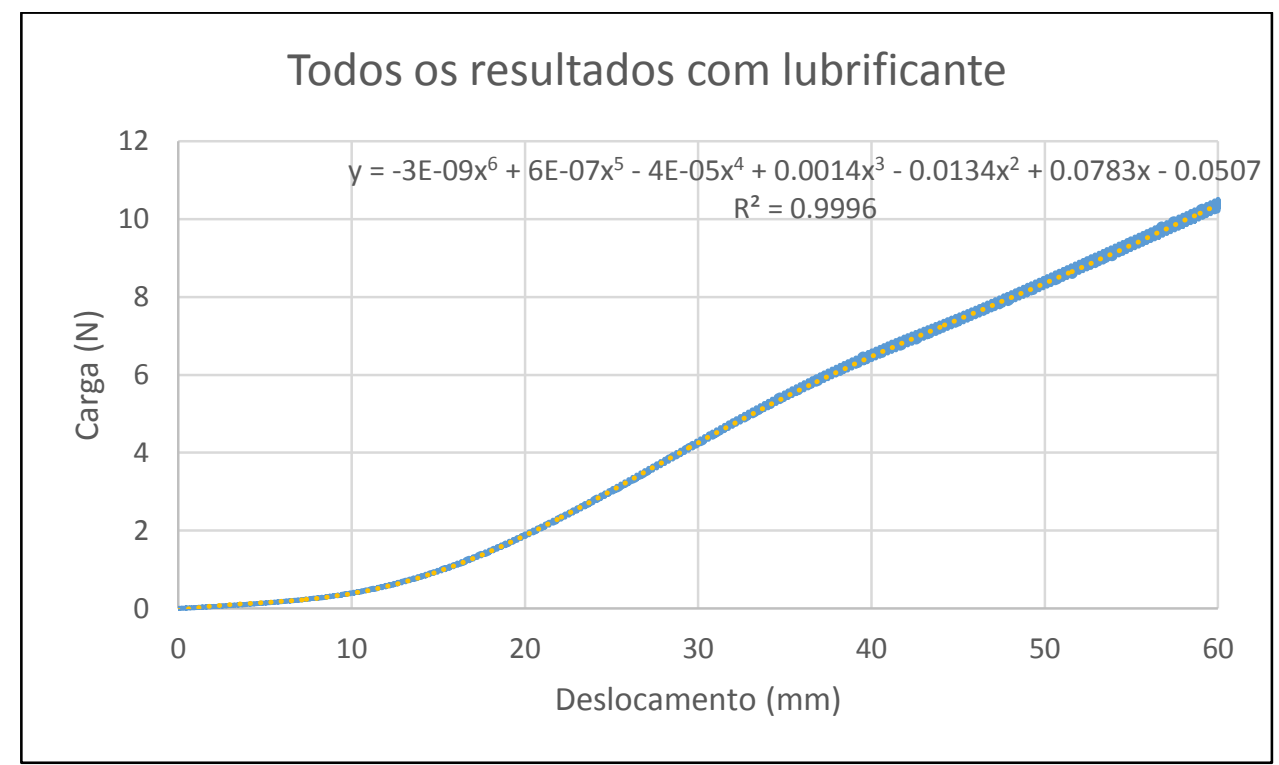

Figura 19 Média de todos os resultados com lubrificante até $60 \mathrm{~mm}$ sem o primeiro ensaio. 


\section{4 - Ensaios com lixa}

Para a realização do ensaio de endentação com lixa, utilizou-se lixa 600 que foi colada no endentor com fita dupla-face $3 \mathrm{M}$ em sua base e em todo seu perímetro até uma altura de 59mm a contar da base do endentor, Fg. 20(a).

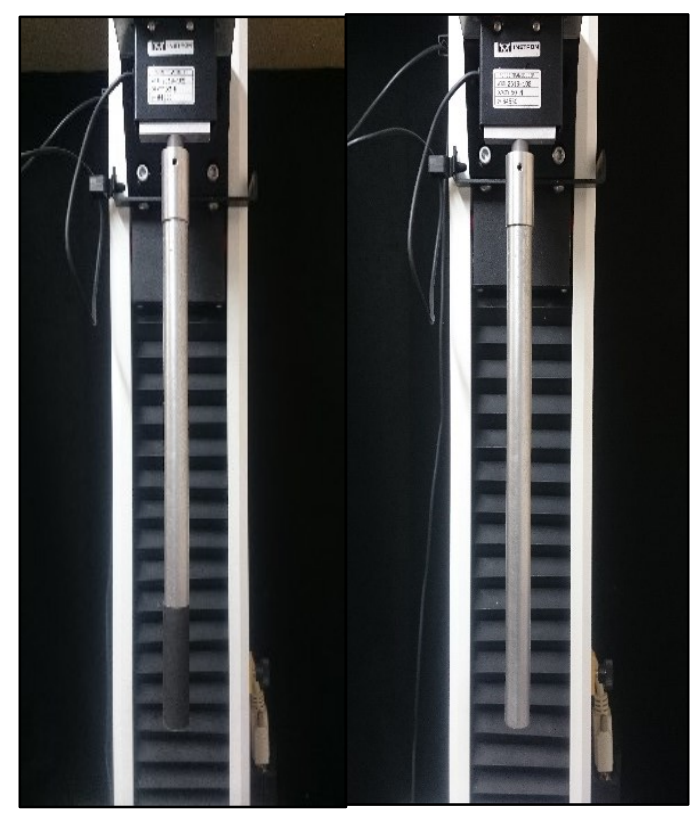

Figura 20 Haste cilíndrica de alumínio com lixa (a) lisa (b).

- Dia 27/04

Foram feitos dois tipos de testes:

1) Cinco testes de endentação contínua até $200 \mathrm{~mm}$ de extensão, Fig. 21. Nestes testes foram coladas no endentor lixas \#600 visando o aumento do atrito no experimento.

2) Cinco testes de endentação com pré condicionamento até $60 \mathrm{~mm}$ de extensão em uma única membrana com a lixa \#600. Foram medidas as cargas no carregamento e descarregamento. 


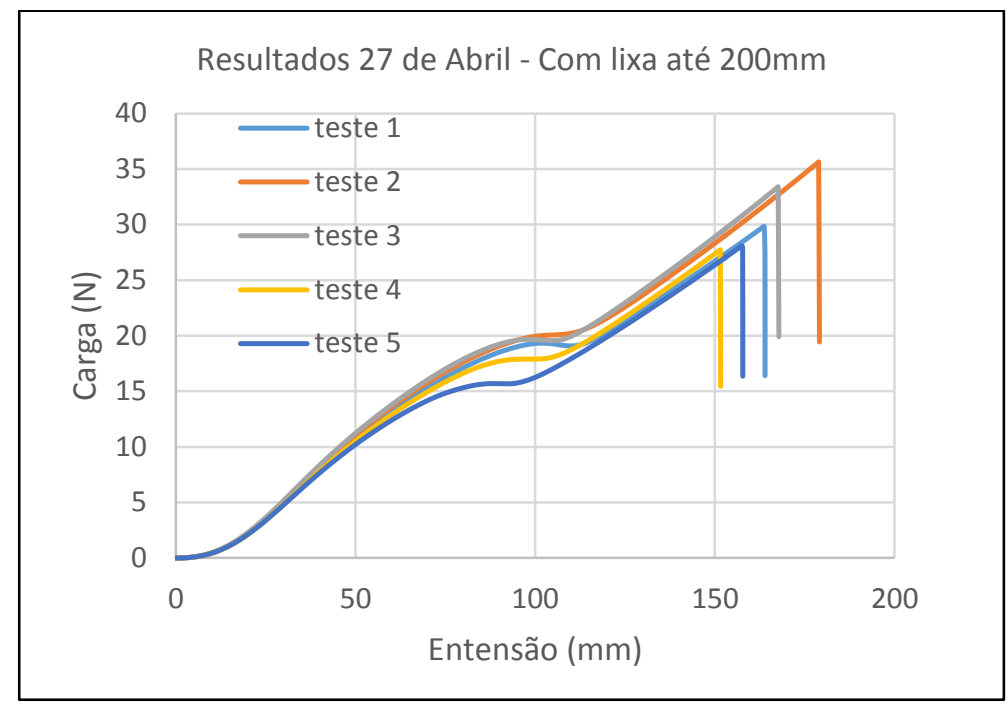

Figura 21 Resultados da endentação até $200 \mathrm{~mm}$.

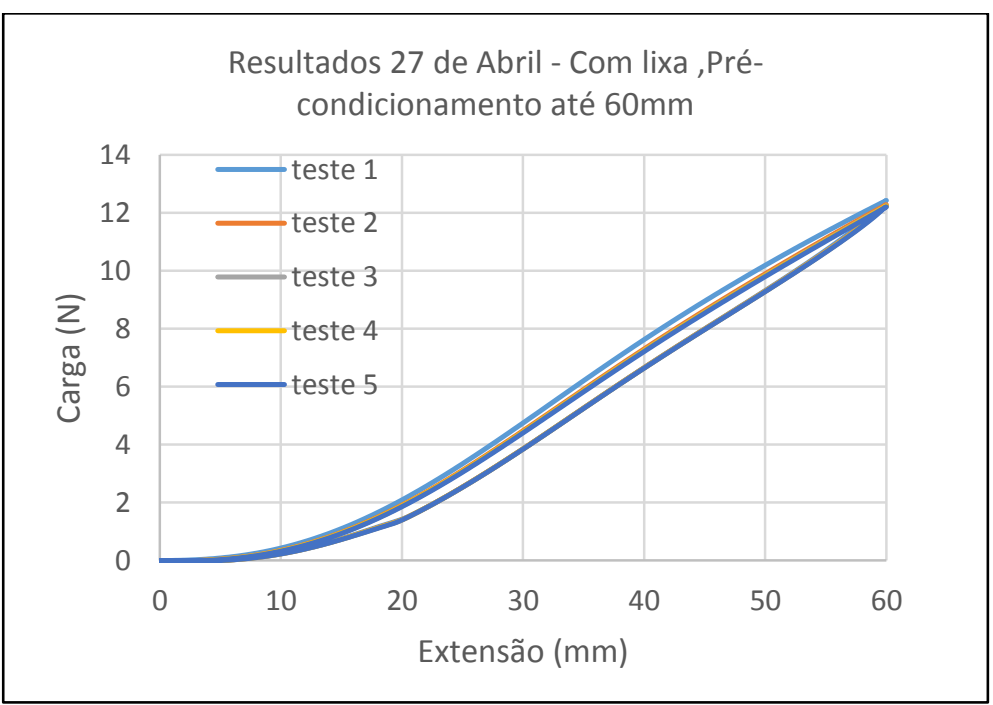

Figura 22 Resultados do pré-condicionamento até $60 \mathrm{~mm}$.

Os resultados nos mostram que a faixa de extensão na qual as membranas romperam é menor que quando lubrificado ou sem lubrificação, ficando entre $150 \mathrm{~mm}$ e $170 \mathrm{~mm}$. Quanto ao pré-condicionamento, percebe-se que as cargas são praticamente idênticas quando analisados os carregamentos sucessivos, portanto não é necessária a realização do pré-condicionamento. 


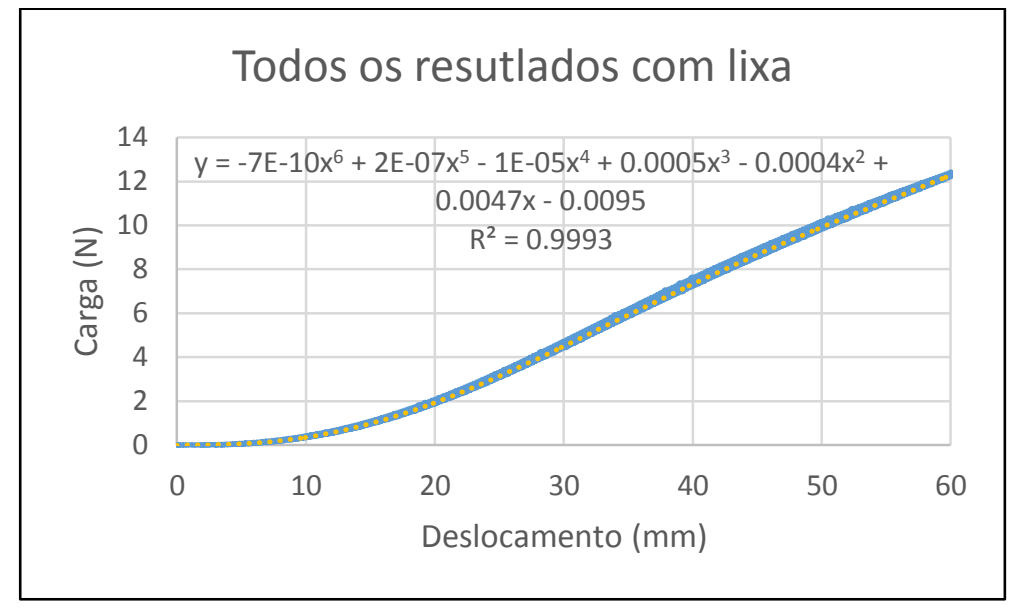

Figura 23 Média de todos os resultados até $60 \mathrm{~mm}$ com lixa 


\section{Comparação de resultados}

\section{1 - Ensaios experimentais}

Da comparação dos ensaios de carregamento com lubrificação para os ensaios sem lubrificação e com lixa, Fig. 24, verifica-se semelhança entre os resultados com lixa e sem lubrificante, estes bastante diferentes do resultado com lubrificante, que para um mesmo deslocamento vertical de um ensaio com lixa necessita uma força $21 \%$ menor.

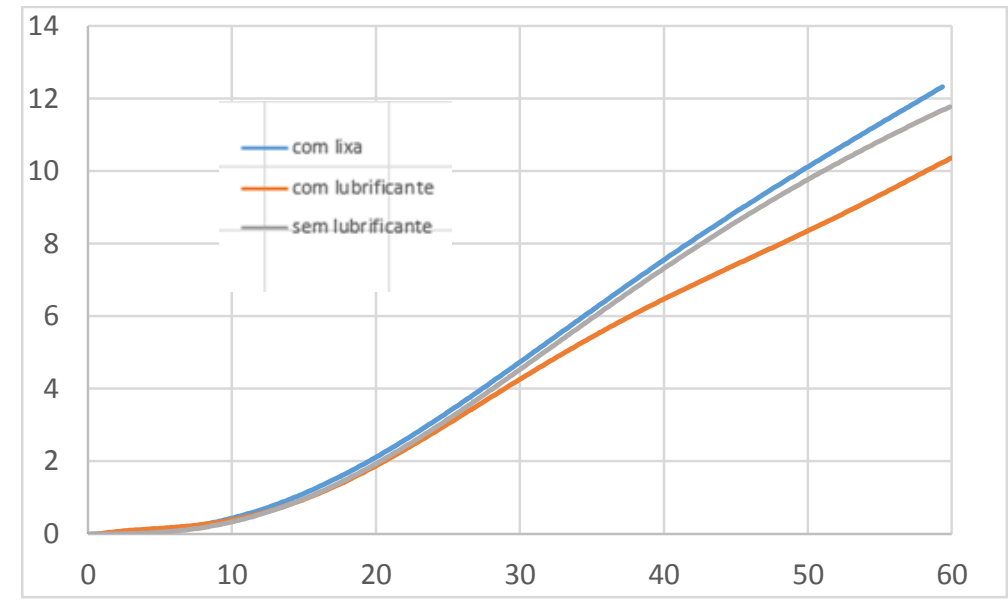

Figura 24 Comparação de ensaios repetidos, sem lubrificante (a), com lubrificante (b) e com lixa (c). 


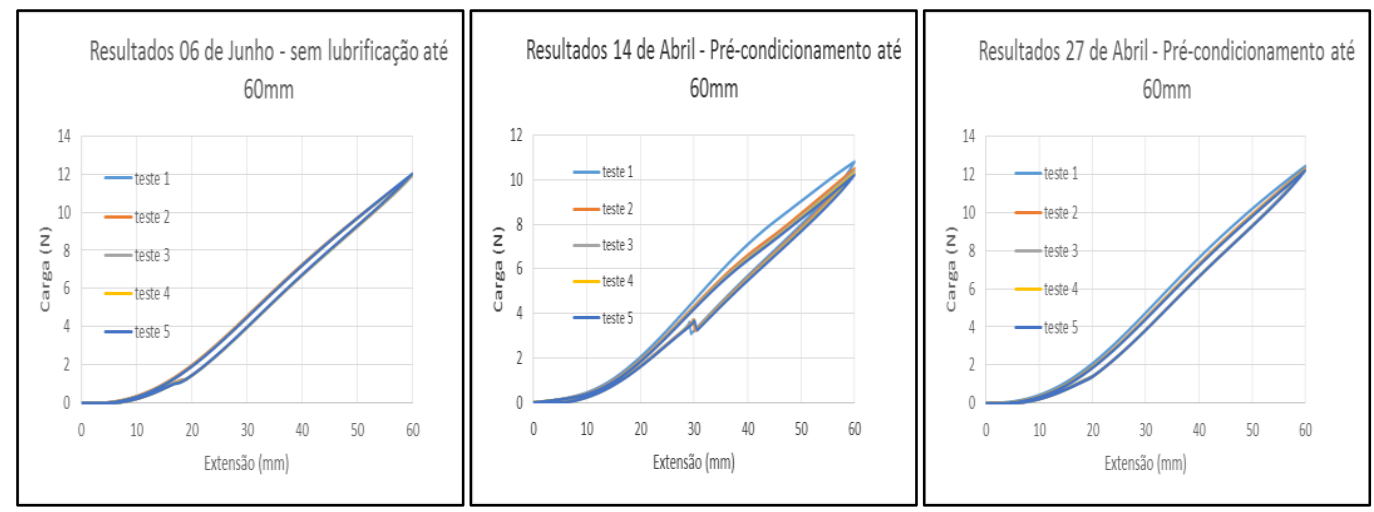

Figura 25 Comparação de ensaios repetidos, sem lubrificante (a), com lubrificante (b) e com lixa (c).

Da comparação dos ensaios de carregamento e descarregamento com lubrificação para os ensaios sem lubrificação e com lixa, Fig. 25, verifica-se que a histerese é muito maior no ensaio com lubrificante e que para um mesmo deslocamento as cargas são $25 \%$ maiores quando há lixa.

\section{2 - Comparação da ruptura}

Na Fig. 26, observa-se as membranas rompidas nos três casos em estudo. Verifica-se que o orifício que caracteriza o rompimento da membrana com lubrificante é menor do que nos outros dois casos, sendo que no caso da lixa o orifício é bastante maior, e perde a regularidade na forma circular. Considerando-se que o rompimento ocorre no bordo circular do endentor, $18 \mathrm{~mm}$ de diâmetro, pode-se afirmar que com lixa a deformação do topo, 4,2mm é 4,3 vezes, enquanto na membrana lubrificada, 3,05mm a deformação é de 5,9 vezes. A membrana lubrificada geralmente não rompe, a da figura chegou a se deslocar até $200 \mathrm{~mm}$ e rompeu ao descarregar. As membranas não lubrificada e em contato com a lixa romperam com deslocamento vertical de $184 \mathrm{~mm}$ e $180 \mathrm{~mm}$, respectivamente. As cargas de rompimento foram $33 \mathrm{~N}$ para a membrana sem 
lubrificação e $35,5 \mathrm{~N}$ para a membrana em contato com a lixa, sendo que esta foi a que rompeu com a maior carga.

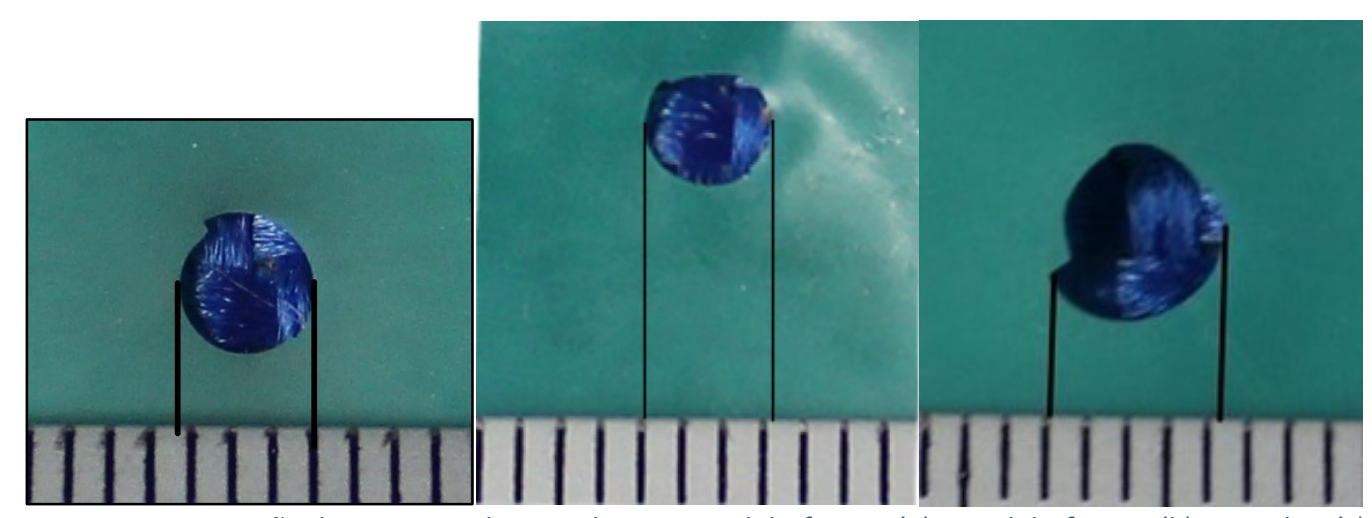

Figura 26 Comparação das rupturas das membranas sem lubrificante (a), com lubrificante (b) e com lixa (c).

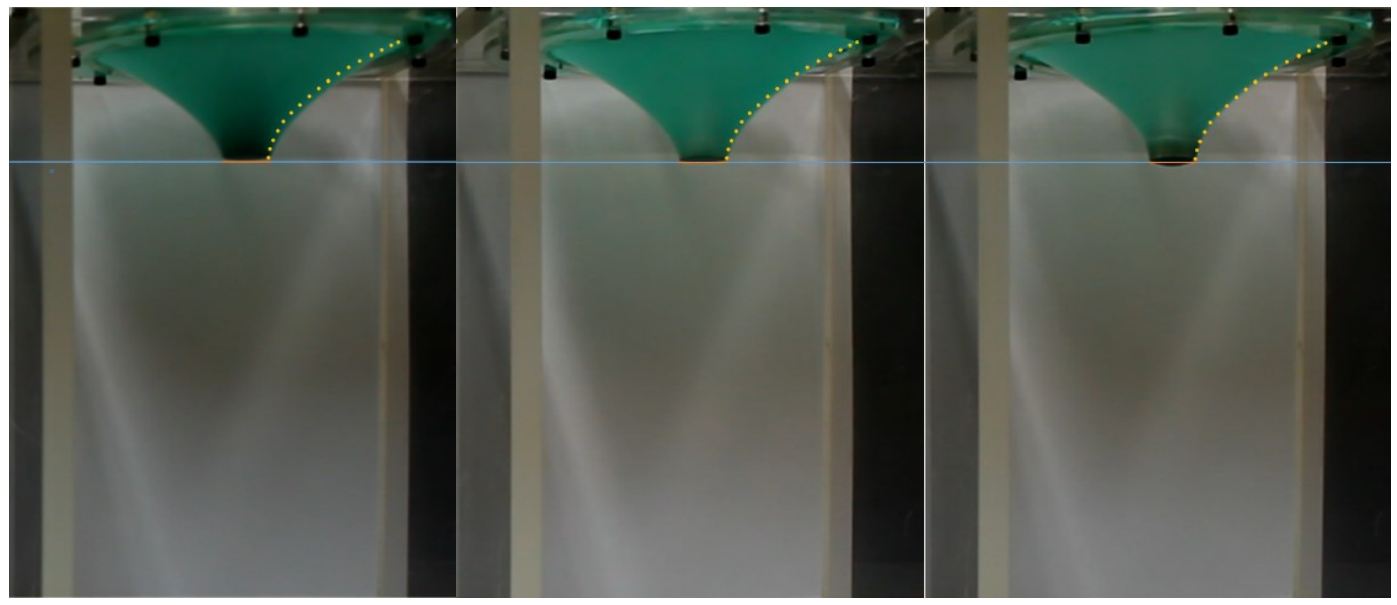

Figura 27 Comparação dos perfis das membranas deformadas em 41mm, com lixa (a), sem lubrificante (b) e com lubrificante (c) tomando como base de comparação o perfil (c).

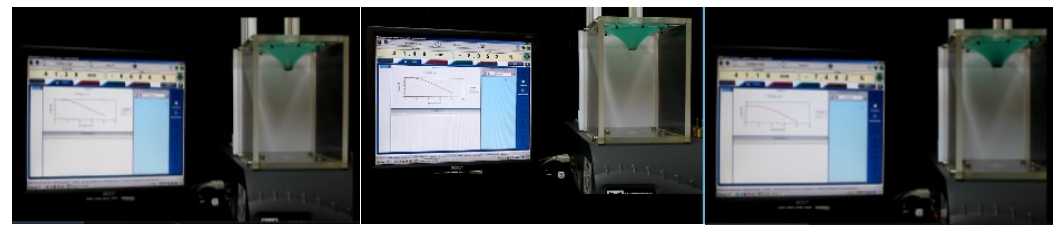

Figura 28 Fotos dos perfis das membranas deformadas em $41 \mathrm{~mm}$, com lubrificante (a), sem lubrificante (b) e com lixa (c). 


\section{3 - Ensaios numéricos e experimentais}

A seguir é apresentada uma comparação entre os resultados numéricos previamente obtidos com os resultados experimentais realizados. Foi utilizado o método dos elementos finitos, procurando-se por parâmetros adequados para a analise numérica.

O método dos elementos finitos consiste, de maneira geral, na formulação computacional da geometria e dando conhecimento às propriedades constitutivas de corpos sujeitos a cargas, variações de temperatura e vibrações, por exemplo. Como resposta são obtidos os campos de deformações e deslocamentos de pontos no corpo em estudo.

Para a análise numérica foi considerada a energia elástica de deformação, $E$, que é obtida pela integração da densidade de energia de deformação, $w$, no volume indeformado da membrana, que é o potencial elástico por unidade de volume indeformado.

$$
\mathrm{E}=\int_{V} w d V
$$

Abaixo é apresentada uma tabela com os diferentes valores da função densidade de energia $w$ para os tipos de materiais propostos.

Tabela 1 Funções de densidade de energia

\begin{tabular}{|c|c|}
\hline Neo-Hookeana & $w=C_{1}\left(I_{1}-3\right)$ \\
\hline Mooney Rivlin & $w=C_{1}\left(I_{1}-3\right)+C_{2}\left(I_{2}-3\right)$ \\
\hline Ogden & $w=\sum_{i=1}^{n} \mu_{n} \frac{\left(\lambda_{1}^{\alpha_{n}}+\lambda_{2}^{\alpha_{n}}+\lambda_{3}^{\alpha_{n}}-3\right)}{\alpha_{n}}$ \\
\hline
\end{tabular}

Onde $I_{1}$ e $I_{2}$ são os invariantes de deformação da membrana e $\lambda_{\mathrm{i}}$ representam as extensões nas direções principais da membrana. 
$\mathrm{Na}$ análise numérica existem dados para ensaios realizados com coeficiente de atrito iguais a 0 e 0,2 . Como não foi feito um estudo sobre o valor exato do coeficiente de atrito obtido nos experimentos com lubrificação, os valores obtidos nos resultados experimentais com lubrificante foram comparados tanto com os resultados numéricos de atrito $\mu=0$ quanto $\mu=0,2$.

Nas tabelas apresentadas a seguir foram consideradas duas colunas de pontos de extensão vertical para comparação numérica e experimental. A primeira coluna indica a extensão onde, segundo o programa numérico, ocorre início da penetração da haste na membrana. O ponto de penetração pode ser considerado como o limiar onde a reta tangente ao perfil lateral da membrana torna-se vertical, isto é, onde começa o contato entre a membrana e a parede do endentor, como é mostrado nas figuras 27, 28 e 29.

1- Resultados numéricos relacionando o coeficiente de atrito e a força necessária para o deslocamento vertical, material Mooney-Rivlin.

$$
\mathrm{w}=\mathrm{C}_{1}\left(\mathrm{I}_{1}-3\right)+\mathrm{C}_{2}\left(\mathrm{I}_{2}-3\right)
$$

$\mathrm{C}_{1}=82,405 \mathrm{kPa}$ e $\mathrm{C}_{2}=99,241 \mathrm{kPa}$, levantados experimentalmente.

Tabela 2 Comparação dos resultados numéricos e experimentais, material Mooney-Rivlin

\begin{tabular}{|c|c|c|c|c|c|c|}
\hline$\mu$ & $\mathrm{F}(\mathrm{N}) / \operatorname{Exp}$ & $\mathrm{d}(\mathrm{mm})$ & $\Delta \%$ & $\mathrm{~F}(\mathrm{~N})$ & $\mathrm{d}(\mathrm{mm})$ & $\Delta \%$ \\
\hline 0.00 & $? / 8,09$ & 46 & & $14,28 / 14,59$ & 90 & $2,2 \%$ \\
\hline 0.20 & $7,2 / 8,48$ & 48 & $17,8 \%$ & $15,3 / 14,59$ & 90 & $-4,6 \%$ \\
\hline 0.46 & $8,4 / 10,36$ & 52 & $23,3 \%$ & $16,2 / 15,33$ & 90 & $-5,4 \%$ \\
\hline 0.80 & $9,3 / 11,98$ & 55 & $28,9 \%$ & $17 / 18,03$ & 90 & $6,1 \%$ \\
\hline
\end{tabular}


2- Resultados numéricos relacionando o coeficiente de atrito e a força necessária para o deslocamento vertical, material Neo Hookeano.

$$
\mathrm{W}=\mathrm{C}_{1}\left(\mathrm{I}_{1}-3\right)
$$

$$
\text { com } \mathrm{C}_{1}=112,32 \mathrm{kPa} \text {. }
$$

Tabela 3 Comparação dos restulador numéricos e experimentais, material Neo Hookeano

\begin{tabular}{|c|c|c|c|c|c|c|}
\hline$\mu$ & $\mathrm{F}(\mathrm{N}) / \operatorname{Exp}$ & $\mathrm{d}(\mathrm{mm})$ & $\%$ & $\mathrm{~F}(\mathrm{~N})$ & $\mathrm{d}(\mathrm{mm})$ & $\%$ \\
\hline 0.00 & $? / 8,81$ & 50 & & $4,2 / 14,59$ & 90 & $247,4 \%$ \\
\hline 0.20 & $? / 9,19$ & 52 & & $5,25 / 14,59$ & 90 & $177,9 \%$ \\
\hline 0.46 & $5,85 / 11,86$ & 70 & $102,7 \%$ & $6,65 / 15,33$ & 90 & $130,5 \%$ \\
\hline 0.80 & $7,62 / 15,21$ & 70 & $99,6 \%$ & $9,5 / 18,03$ & 90 & $89,7 \%$ \\
\hline
\end{tabular}

3- Resultados numéricos relacionando o coeficiente de atrito e a força necessária para o deslocamento vertical, material Ogden de primeira ordem.

$$
\mathrm{W}=\sum_{p=1}^{N} \frac{\mu_{p}}{\alpha_{p}}\left(\lambda^{\alpha_{p_{1}}}+\lambda^{\alpha_{p_{2}}}+\lambda^{\alpha_{p_{3}}}-3\right)
$$

$\alpha_{1}=1,608$ e $\mu_{p}=306,972 \mathrm{kPa}$, levantados experimentalmente. 
Tabela 4 Comparação dos resutlados numéricos e experimentais, material Ogden ordem 1

\begin{tabular}{|c|c|c|c|c|c|c|}
\hline$\mu$ & $\mathrm{F}(\mathrm{N}) / \operatorname{Exp}$ & $\mathrm{d}(\mathrm{mm})$ & $\%$ & $\mathrm{~F}(\mathrm{~N})$ & $\mathrm{d}(\mathrm{mm})$ & $\%$ \\
\hline 0.00 & $4,88 / 7,69$ & 44 & $57,6 \%$ & $6,2 / 14,59$ & 90 & $135,3 \%$ \\
\hline 0.20 & $5,0 / 8,26$ & 47 & $65,2 \%$ & $? / 14,59$ & 90 & \\
\hline 0.46 & $6,9 / 13,29$ & 60 & $92,6 \%$ & $11,6 / 15,33$ & 90 & $32,2 \%$ \\
\hline 0.80 & $10,1 / 16,28$ & 76 & $61,2 \%$ & $11,6 / 18,03$ & 90 & $55,4 \%$ \\
\hline
\end{tabular}

4- Resultados numéricos relacionando o coeficiente de atrito e a força necessária para o deslocamento vertical, material Ogden de segunda ordem.

$$
\begin{aligned}
& \mathrm{W}=\sum_{p=1}^{N} \frac{\mu_{p}}{\alpha_{p}}\left(\lambda^{\alpha_{p_{1}}}+\lambda^{\alpha_{p_{2}}}+\lambda^{\alpha_{p_{3}}}-3\right) \\
& \mu_{1}=64.881 \mathrm{kPa}, \mu_{1}=294.097 \mathrm{kPa}, \alpha_{1}=2.619 P a \quad \text { e } \quad \alpha_{2}=0.385 \mathrm{~Pa} \text {, levantados }
\end{aligned}
$$

experimentalmente

Tabela 5 Comparação dos resultados numéricos e experimentais, material Ogden ordem 2

\begin{tabular}{|c|c|c|c|c|c|c|}
\hline$\mu$ & $\mathrm{F}(\mathrm{N}) / \operatorname{Exp}$ & $\mathrm{d}(\mathrm{mm})$ & $\%$ & $\mathrm{~F}(\mathrm{~N})$ & $\mathrm{d}(\mathrm{mm})$ & $\%$ \\
\hline 0.00 & $4,8 / 7,92$ & 45 & $65 \%$ & $6,2 / 14,59$ & 90 & $135,3 \%$ \\
\hline 0.20 & $6,45 / 8,79$ & 50 & $36,3 \%$ & $7,1 / 14,59$ & 90 & $105,5 \%$ \\
\hline 0.46 & $9,2 / 11,34$ & 57 & $23,3 \%$ & $11,8 / 15,33$ & 90 & $29,9 \%$ \\
\hline 0.80 & $10,1 / 14,25$ & 65 & $41,1 \%$ & $13,6 / 18,03$ & 90 & $32,5 \%$ \\
\hline
\end{tabular}




\section{Conclusões}

Pela análise e comparação dos resultados obtidos experimental e numericamente, podemos concluir que o comportamento apresentado pelas membranas nos diferentes tipos de ensaios realizados foi mais bem representado pela modelagem numérica apresentada pelas equações que regem o comportamento do material de Mooney-Rivlin, principalmente para extensões mais elevadas, onde a diferença percentual entre o valor das cargas nos resultados experimental e numérico foi bastante pequena em todos os tipos de ensaio. A adequação do modelo a extensões menores ainda é objeto de estudo.

A seguir são mostradas nas figuras 29,30 e 31 os perfis laterais das membranas no ensaio de endentação nos momentos referentes às extensões onde, segundo o modelo numérico de Mooney-Rivlin, ocorreu o início penetração do endentor nas membranas. As figuras mostram os perfis para os três tipos de ensaio realizados (sem lubrificação, Fig. 29, com lubrificação, Fig. 30 e com lixa, Fig. 31) com retas tracejadas que representam as respectivas retas tangentes. Segundo o modelo numérico de Mooney-Rivlin, para o ensaio sem lubrificante $(\mu=0,46)$, a penetração se dá com extensão de 52mm. Para o ensaio com lubrificação (considerando o ensaio lubrificado análogo ao modelo numérico $\operatorname{com} \mu=0,2$ ), o ponto de início da penetração se deu com uma extensão vertical de $48 \mathrm{~mm}$. Por fim, para o caso com atrito $(\mu=0,8)$, o ponto de penetração se deu em $55 \mathrm{~m}$ de extensão. 


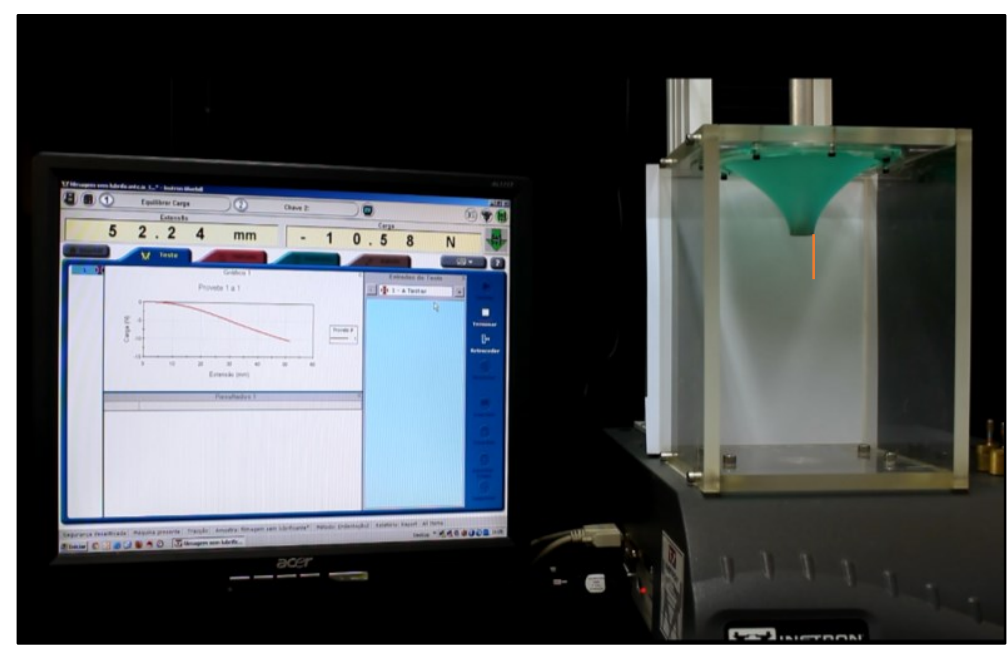

Figura 29 Perfil lateral do ensaio sem lubrificante

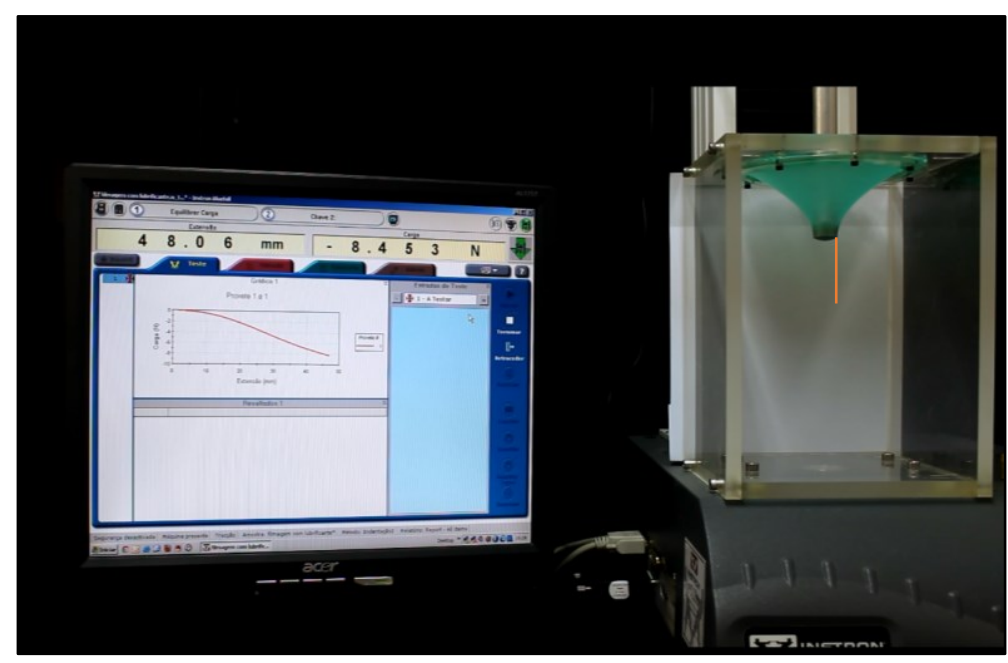

Figura 30 Perfil lateral do ensaio com lubrificante. 


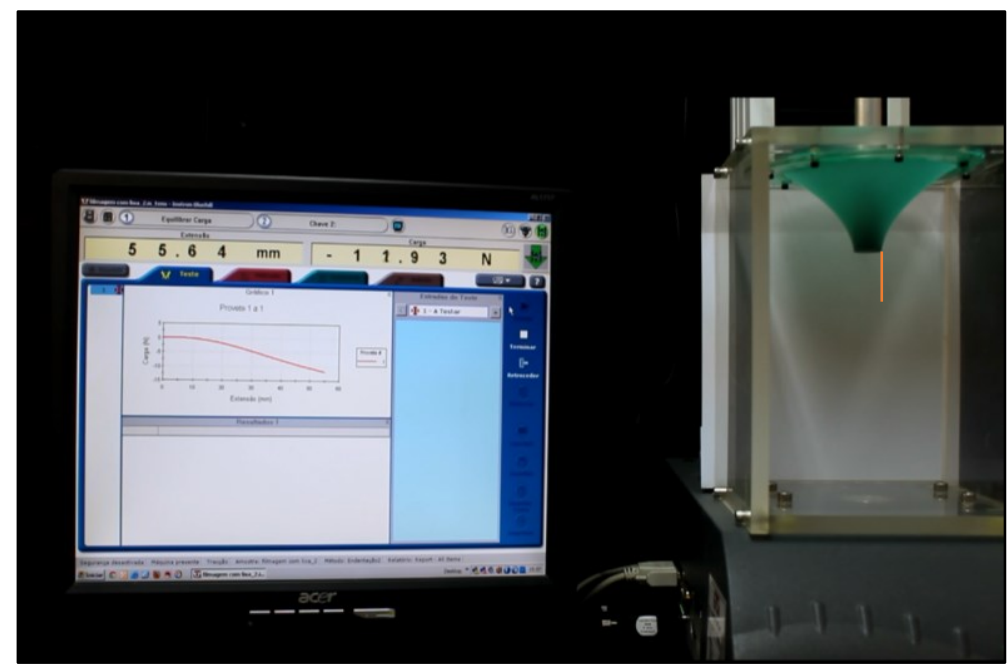

Figura 31 Perfil lateral do ensaio com lixa.

Pela observação das figuras 29, 30 e 31 e com o auxílio das retas tangentes desenhadas, podemos perceber que os valores de extensão calculados numericamente segundo o material de Mooney-Rivlin para as penetrações se aproximam bastante com os modelos experimentais. Analisando os resultados experimentais, Fig.32, que mostra as médias dos ensaios sem lubrificação, com lubrificação e com lixa, os valores das extensões mencionadas são próximos dos pontos da primeira inflexão das curvas.

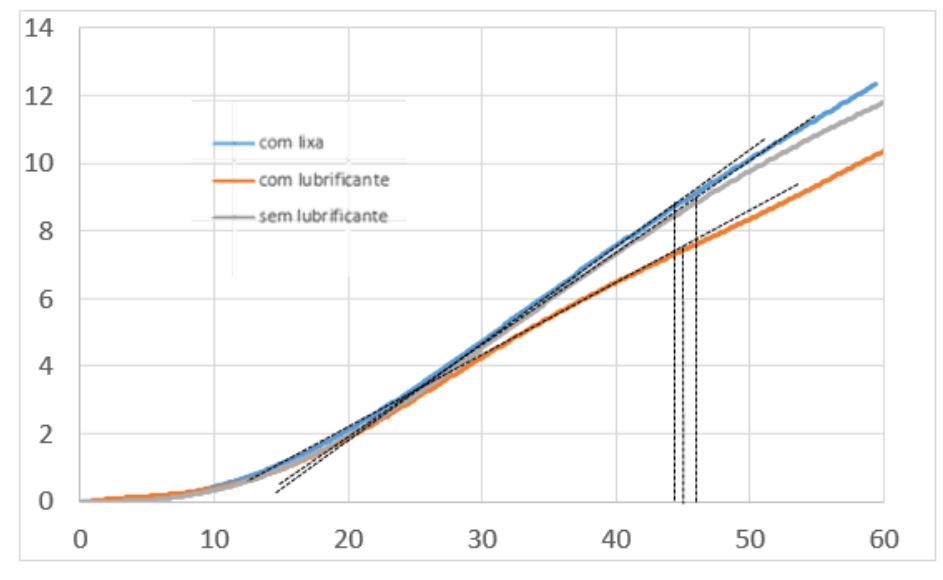

Figura 32 Ensaios e retas tangentes aos primeiros pontos de inflexão. 
Pela análise dos gráficos, percebe-se que o crescimento bastante monotônico das curvas do início do carregamento até o segundo ponto de inflexão dificulta a identificação do ponto exato de onde a mesma ocorre, portanto pode-se considerar razoável a modelagem por MooneyRivlin dos pontos onde ocorre penetração do endentor na membrana. Outra dificuldade encontrada na hora da definição do ponto de penetração se deve ao fato de que, visualmente, não é possível precisar o momento em que se pode observar um perfil vertical. O segundo ponto de inflexão recorrente nas curvas em todos os tipos de testes não revelou nenhum fenômeno que se pôde observar visualmente até o momento.

\section{Bibliografia}

1- Arruda, E.M.; Boyce, M.C.,“A three-dimensional constitutive model for the large stretch behaviour of rubber elastic materials", Journal of the Mechanics and Physics of Solids 41, 389-412, 1993.

2- Fu, Y.B.; Ogden, R.W., Nonlinear Elasticity - Theory and Applications, Cambridge University Press, Cambridge, 2001.

3- Green, A.E.; Adkins, J.E., Large Elastic Deformations and Non-Linear Continuum Mechanics, Oxford University Press, Oxford, 1960.

4- Libai, A.; Simmonds, J.G., The Nonlinear Theory of Elastic Shells, Cambridge University Press, Cambridge, 1998.

5- Ogden, R.W., "Large deformation isotropic elasticity on the correlation of theory and experiment for incompressible rubber-like solids", Proceedings of the Royal Society of London, vol. A326, London, pp. 565-584, 1972.

6- Ogden, R.W., Non-linear Elastic Deformations, Ellis Horwood Ltd., Chichester, 1984. 
7- Pamplona, D.C.; Weber, H.I.; Sampaio, G.R., "Analytical, numerical and experimental analysis of continuous indentation of a flat hyperelastic circular membrane by a rigid cylindrical indenter". International Journal of Mechanical Sciences, v. 87, p. 18-25., 2014.

8- Selvadurai, A.P.S., "Deflections of a rubber membrane", Journal of the Mechanics and Physics of Solids 54, 1093-1119, 2006.

9- Saccomandi, G.; Ogden,R.W., Mechanics and Thermomechanics of Rubberlike Solids, Springer, Wien, 2004.

10- Yeoh, O.H., Some forms of the strain energy function for rubber, Rubber Chemistry and Technology, 66, 754-771, 1993.

11-Sampaio, G.R., Análise numérica e experimental de endentação em membranas hiperelásticas planas. Dissertação de Mestrado pelo Departamento de Engenharia Mecânica da PUC-RIO, 2013. 